\title{
Molecular map of GNAO1-related disease phenotypes and reactions to treatment
}

\author{
Ivana Mihalek ${ }^{\mathrm{a},}$, Meredith Park ${ }^{\mathrm{b}}$, McKenna Kelly ${ }^{\mathrm{b}, \mathrm{c}}$, Jeff L. Waugh ${ }^{\mathrm{d}, \mathrm{e}}$, \\ Annapurna Podurib,d,f, and Olaf Bodamer ${ }^{\mathrm{a}, *}$ \\ aDivision of Genetics and Genomics, Boston Children's Hospital, \\ Harvard Medical School, Boston, MA, USA \\ bepilepsy Genetics Program, Department of Neurology, Boston \\ Childrens Hospital, Boston, MA, USA \\ ${ }^{c}$ Present: Dartmouth Medical School, Hanover, NH, USA \\ ${ }^{\mathrm{d}}$ Department of Neurology, Harvard Medical School, Boston, MA, USA \\ eMovement Disorder Clinic, Department of Neurology, Boston \\ Childrens Hospital, Boston, MA \\ ${ }^{\mathrm{f} D i v i s i o n}$ of Epilepsy and Clinical Neurophysiology, Boston Childrens \\ Hospital, Boston, MA \\ ${ }^{*}$ Correspondence: ivana.mihalek@childrens.harvard.edu, \\ olaf.bodamer@childrens.harvard.edu
}

December 10, 2017

The GNAO1 gene codes for the most commonly expressed $\mathrm{G} \alpha$ protein in the central nervous system. De novo GNAO1 variants cause complex early-onset neurological phenotypes, sometimes with distinct epilepsy or movement disorder manifestations, and sometimes with both manifestations in the same patient. G-protein coupled receptor (GPCR) signaling is among the best studied molecular interaction pathways in the human organism, which provides the input needed to quantitatively evaluate how mutations modify the GPCR signal. This in turn allows rational interpretation of distinct phenotypes arising from mutations in GNAO1. In this work we outline a model that enables understanding of clinical phenotypes at a molecular level and anticipating symptoms and treatment response for future patients. We show that apparently similar mutations in GNAO1 can lead to distinct phenotypes through distinct modulation of the incoming GPCR signal. Specifically, the epileptic phenotype arises necessarily in mutations affecting the catalytic pocket. Cases with movement disorders separate into two groups, responsive or nonresponsive to dopamine, corresponding, respectively, to the interfaces with GPCR and GNAO1s downstream effector. Mutations placed very close to either of these two interfaces may manifest as a movement disorder phenotype without epilepsy. In addition to the practical 
implications for decision making process in choosing therapy for GNAO1 patients, this system provides a precision medicine paradigm in which individual genomic information and understanding of the implications of variants at the molecular level can inform and guide the treatment process.

\section{Introduction}

As the reports of disease causing variants in GNAO1 gene accumulated over the last five years [1-5], and the first compilation works started to appear [6-9], a picture emerged of a source of complex phenotypes, with equally complex and sometimes contradictory responses to treatment.

GNAO1, guanine nucleotide binding protein, subunit $\alpha$, type "o", is the most common type of G $\alpha$ in the central nervous system. It functions at the core of multiple neurotransmitter pathways, and is expressed in multiple types of neurons [10]. Unsurprisingly then, GNAO1 mutations cause a spectrum of neurological phenotypes, roughly falling into two categories: movement disorders (MD) or epilepsyrelated (E) phenotypes. While most patients manifest symptoms from both categories, some patients have exclusively MD or E manifestations. It must be noted, however, that as these phenotypes were recognized only recently, and the identified patients tend to be severely affected, the full spectrum of GNAO1-related disease in humans is not fully appreciated. The most frequent MD phenotype is chorea, though the spectrum can include or be limited to myoclonus or dystonia. Epilepsy-related disorders are typically early-onset, often with status epilepticus and/or seizures refractory to multiple medications but occasionally with mild seizures. These epilepsy-dominant patients universally have global developmental delay, and typically manifest stereotypies and difficulty with motor coordination. While the movement and epilepsy phenotypes may overlap, the fact that one pattern typically dominates and the two may segregate completely suggests that distinct classes of molecular abnormality underlie GNAO1-related symptoms. Their pharmacological treatment typically consists of reducing neuronal excitability for epilepsy phenotypes, and manipulation of dopamine either increasing or decreasing its availability, depending on the type of abnormal movement for the MD phenotypes. The challenge for the classification and characterization of molecular lesions is to reconcile these seemingly contradictory treatment requirements and predict medication efficacy, thus reducing side effects and time to benefit.

In this work we show that even though the concrete aspects of phenotype in this system may depend on the individual genome background and development history, the genotype-phenotype correlation can be rationalized by considering the core G protein signaling loop, and the way in which disease-related mutations modify the signal.

\section{Molecular players in GNAO1 signaling pathway}

The model we describe below centers on the GPCR signaling as a membrane bound GTP-ase signaling pathway [11], SI Fig. S1, with its three obligate components: a GTPase, a guanine nucleotide exchange factor (GEF), and a GTPase-activating protein (GAP). It is a particular feature of GPCR signaling, in contrast to the signaling through small GTPases, that the GTPase, G $\alpha$, forms a firm complex with $\mathrm{G} \beta \gamma[12]$. This complex dissociates upon the interaction with activated GPCR, creating a branching, or bipartite, signal [13], with $\mathrm{G} \alpha$ and $\mathrm{G} \beta \gamma$ independently influencing their downstream effectors.

\section{GTPase: GNAO1}

GNAO1 is severalfold more abundant than any other G $\alpha$ protein in the central nervous system [10]. Also, neurons and neuroendocrine cells are the primary site of expression of the gene [14], consistent with the phenotype observed in GNAO1 patients. Known G $\beta \gamma$ partners of GNAO1 are encoded by GNB1 (as G $\beta$ ) and GNG2 (as G $\gamma$ ) [15], though the existence of other partners is likely. As is the case with GNAO1, GNB1 and GNG2 are preferentially expressed in brain [16]. Of the five genes coding 
for $\mathrm{G}_{\beta}$ [17], GNB1 is the only one that has been related to autosomal dominant neurodevelopmental disease phenotypes [18].

\section{GEF: G-protein coupled receptor (GPCR)}

GNAO1 proteins are known to interact with GPCRs from the GABA, adrenergic, dopamine, and muscarinic group, and more [14], underscoring the diversity and extent of systemic damage incurred with GNAO1 mutations. When activated by their respective agonist, GPCRs act as GEFs for GNAO1. A special role is played by DRD2, a GPCR from $\mathrm{D}_{2}$-like dopamine receptor family that parteners with GNAO1. It can act either as a typical post-synaptic receptor (isoform D2Lh), or pre-synaptically, as an autoreceptor that negatively regulates neurotransmission through a feedback mechanism (isoform D2Ls) [19].

\section{GAP: RGS protein}

Multiple RGS proteins accelerate the GTPase activity of GNAO1, including RGS1, RGS16, and GAIP, and almost certainly others. This interaction is possibly competing with the effector binding [10], though the structural evidence is ambiguous on the latter (SI, Fig. S2).

\section{Effectors of $\mathbf{G} \alpha$ and $\mathbf{G} \beta \gamma$}

The prototypical downstream effectors of GNAO1 signaling are adenylate cyclase for $\mathrm{G} \alpha$, and ion channels, phospholipase $\mathrm{C}-\beta$, or phosphoinositide-3-kinase for $\mathrm{G} \beta \gamma$ [14]. GNAO1 functions as inhibitor of adenylate cyclase (AC) in vitro [20]. This interaction is further supported by recently established connection between mutations in adenylate cyclase 5 and movement disorders [21, 22]. In parallel, GNAO1's partner G $\beta \gamma$ regulates calcium, potassium and sodium ion channels [10, 23]. The potassium channels KCNQ2 and GIRK, in particular have been implicated, respectively, in the early infantile epileptic encephalopathy (EIEE) [24] and general epileptic phenotypes in human and in animal models [25]. GIRK, in addition, has been reported to be directly regulated by $\mathrm{G} \beta \gamma$ in cardiac myocytes, though the subunit through which $\mathrm{G} \beta \gamma$ regulates GIRK is the heart specific GIRK4, homologous to the neuronal counterparts GIRK2 and GIRK3 [26].

With the mediators of signaling downstream of GNAO1 only partly understood at the time of this writing, we investigated what can be learned from he core GTPase cycle, without knowing the precise mechanism through which the effectors create the phenotype, or even without knowing the effectors' exact identity.

\section{Stoichiometry of the GPCR signaling system.}

Modeling the system requires several quantitative assumptions, or parameters, as the input (Methods). In particular, we need a reasonable estimate of the relative abundance ratios of different components in the GPCR signaling system.

The stoichiometry of the GPCR signaling system has been a matter of debate, Ostrom et al. [27], for example, put the ratio of receptor:G protein:effector to 1:100:3, in the system of $\beta$-adrenergic receptor signaling through adenylyl cyclase via $G_{s}$. However, there is increasing evidence that the GPCR signaling machinery does not diffuse freely through the membrane, but that the receptors form homo- and heterodimers, [28, 29], perhaps further organizing into 2:2 receptor heterotetramers, [30], and higher order paracrystalline arrays [31]. Furthermore, the results of Nobles et al. [32] show that GPCR dimers can pre-form pentameric associations with G-protein trimers, even in the absence of the agonist. This suggests the 2:1:1 ratio for receptor:G protein:effector. It can be shown (SI, Fig. S3) that doubling the relative amount of any component changes somewhat the intensity of the signal, but not the relative impact of the mutations. Therefore, in the discussion' below, we will take that the receptor:G protein:effector ratio is 1:1:1. 
Since the cell maintains an abundant level of GTP [33], we take that GTP is always and instantly available, and not a rate limiting step in any of the interactions [34].

\section{GPCR pathway, a biochemically well studied system}

The other big group of input parameters are the forward and reverse rates for the biochemical reactions in the GPCR pathway. The ability to build a quantitative model of GPCR system, in contrast to many other interesting signaling pathways, comes from the fact that the system and its components have been under intense biochemical investigation for several decades. Of particular interest here are $\mathrm{G} \alpha$ mutants that do not bind nucleotide [35-37]. They have two peculiar properties of blocking its native GPCR, while not binding its G $\beta \gamma$. These properties result in a unique distortion of the GPCR signal (Fig. 2, 'empty pocket').

\section{Modeling a system of biomolecular reactions}

We model the GPCR signaling system as a set of reaction rate equations [38], in which the relative concentrations of molecular species (complexes and individual molecules) change in a mutually interdependent way - products of one reaction being the input into another - and all details of the interactions are hidden in the rate constants (SI, Fig S4).

\section{Results}

\section{Signal transduction in the wild-type GPCR system}

$\mathrm{G} \alpha$, exemplified by GNAO1, is the core actor in the GPCR signaling. Before the arrival of the agonist signal, most of the G $\alpha$ is inactivated by the GDP in its catalytic pocket, and tied in G trimer with $\mathrm{G} \beta \gamma$. For all practical purposes, the exchange of GDP for GTP never happens spontaneously, and the system is thus paused in the equilibrium state (Fig. 1A).

The signal consists in taking the system out of this equilibrium, and letting it relax back. The arrival of the signal, from the perspective of the G-trimer, consists of an active guanine-nucleotide exchange factor (GEF) appearing in the system, with the main effect of enabling the replacement of GDP with GTP. In the GPCR-signaling system, the GEF is the GPCR itself. The 'appearing' - in the functional sense - of the GPCR is the allosteric response to extracellular agonist binding. The ensuing GDP for GTP exchange is accompanied by the disassembly of the trimer and its release from the receptor. From this point on, the signal branches in two directions. In the context of this work, G $\beta \gamma$ is traditionally related to epileptic phenotype (if deregulated), through its interaction with potassium channels, and $\mathrm{G} \alpha$ regulating cAMP signaling, implicated in movement disorders. The cycle of interactions (not to be confused with the signal) is closed with $\mathrm{G} \alpha$ catalyzing the GTP hydrolysis, followed by the reassembly of the G-trimer.

Each of these interactions is an ongoing process that repeats as long as the participating entities are available. Thus, the overall effect of an active GEF is the repartitioning of the available G $\alpha$ and G $\beta \gamma$ into an active population, consisting of GTP-bound $\mathrm{G} \alpha$ and $\mathrm{G} \beta \gamma$ bound to their respective effectors, and the populations of free and GPCR bound G-trimers (Fig. 1B). The relative size of each molecular population depends on the ratio of interaction rates (SI, Fig. S5).

Once the signal is terminated (by removal of the GPCR agonist) the system begins its return to the original, equilibrium state. The resulting effect is that a brief salvo of agonist molecules results in an intracellular signal extended in time, of a characteristic shape [39], shown in (Fig. 1C). The GPCR-G signal decays on the timescale of seconds to tens of seconds [40,41], depending on the mechanism through which the agonist appears and is removed from the system [42]. In our model we use an acetylcholine-like mechanism, in which the agonist molecule is removed by the action of acetylcholinesterase (AChE). AChE cleaves the agonist and thus removes it from the system. It 
A)

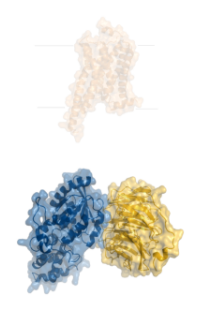

no agonist

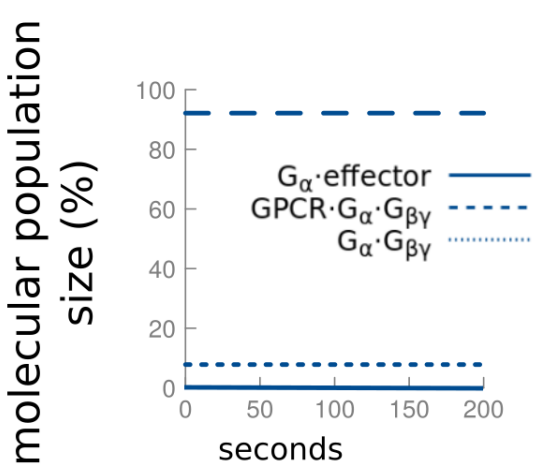

B)

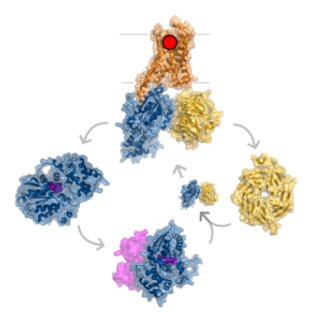

agonist added

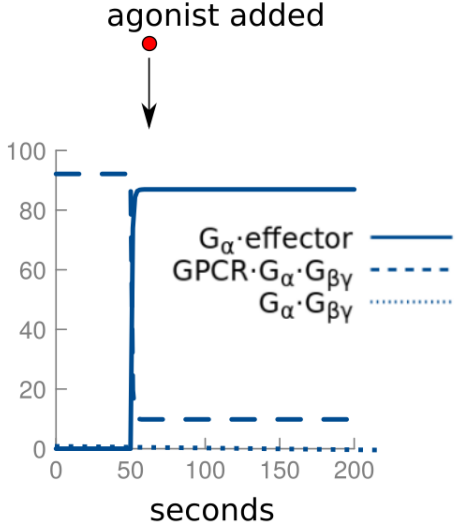

C)

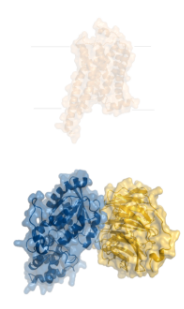

agonist added/removed

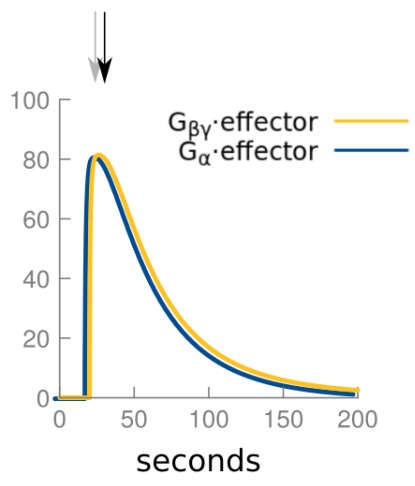

Figure 1: GPCR signal transiently takes the system out of its equilibrium state. A) Without agonist present, all $\mathrm{G}$ units are bound in trimers. B) With agonist, the units cycle between trimer, activation by GPCR, interaction with effectors and deactivation with the help of RGS. C) Signal: agonist appears, it is removed, and the system returns to its original state. Blue lines: $\mathrm{G} \alpha$. Yellow lines: $\mathrm{G} \beta \gamma$. The interacting partner is indicated by dot notation.

should be understood as a stand-in for all agonist removal mechanisms used by a GPCR system (such as dopamine reuptake) which may modify the timescale but not the signaling cycle itself.

As a measure of the strength of the signal traveling along each of the two branches, in Fig. $1 \mathrm{C}$ we show the fraction of the total amount of $\mathrm{G} \alpha$ and $\mathrm{G} \beta \gamma$ interacting with their respective effectors. In our discussion this interaction is assumed to result in the regulation of ion current by G $\beta \gamma$ and adenylyl cyclase inhibition by $\mathrm{G} \alpha$, which are not explicitly modeled.

\section{Signal modification through changing reaction rates in GPCR cycle}

The height and the shape of the signal depend on the catalytic rate of GNAO1, as well as its affinity for the other molecules in the core signaling cycle. These properties - in our model reflected in the reaction rates (SI, Fig. S1) - can be modified by mutations in the peptide, depending on the physical properties of the replacement. In principle, each mutation will have some effect on each of the interactions in the system. However, the relative size of the impact on various interaction interfaces is expected to depend on the distance/proximity to each of them. When designing a platform for decisions in precision medicine, the change in reaction rates should be either evaluated in molecular simulation, or determined experimentally. For the purposes of the model presented, we chose to limit our assessment of random mutations to those that weaken an interaction (rather than making it stronger), and observe signal propagation through the system given that reduced interaction. In all of the clinical cases reported so far, the mutation was dominantly inherited; therefore, in our simulations only half of the G $\alpha$ population is mutated, as would be the case in de novo carriers. 


\section{Modifying the reaction rates for GPCR-G trimer binding and nucleotide exchange}

Changing the interaction with GPCR changes the rate for GPCR-G trimer binding, as well as the rate for the nucleotide exchange and the release of the activated subunits (Fig. 2, GPCR.G G $_{\alpha}^{D}$ SI, Fig. S6 for the rates changed from the wild-type values in computational experiments, Fig. 2). The helix through which G $\alpha$ interacts with GPCR is far enough from the catalytic pocket to assume that the rate of GTP to GDP conversion is not affected. In our simulations, as long as there is some residual interaction between G $\alpha$ and GPCR, the signal can be completely rescued to wild type levels by increasing the level of agonist in the system; it is also the only signal modification for which this correction works (SI, Figs. S7 and S8).

\section{Modifying the reaction rates of $\mathbf{G} \alpha$ coupling to its effector}

This introduces the simplest signal modification in our model system. Any mutation that interrupts this interaction is expected to degrade exclusively the branch of the signal traveling in that direction (Fig. 2, $\mathrm{G}_{\alpha}^{T}$.effector $\alpha$ ).

\section{Modifying the rate of GTP hydrolysis}

Mutations affecting the interface with RGS, and those changing the geometry of the catalytic pocket (without causing steric hindrance) can be expected to have similar impact on the system, through modifying the GTP to GDP conversion rate, and thus broadening the signal profile (Fig. 2 , RGS.G ${ }^{T} \alpha$ and $\mathrm{GTP} \rightarrow \mathrm{GDP}$ ). Paradoxically, the poorer the performance of GNAO1 as the catalyst, the higher and broader the signal.

\section{Multiple effects of abolished nucleotide binding on reaction rates in GPCR-G signaling cycle}

Mutations that completely abolish nucleotide binding ('empty pocket' mutants) lead to de-activation of a portion of GPCR and G $\alpha$ itself [37], and even more importantly, to creation of a population of active $\mathrm{G} \beta \gamma$ units present in the system, which may create supra-threshold spike once the remaining half of the $\mathrm{G} \beta \gamma \mathrm{s}$ is released upon GPCR activation (Fig. 2, 'empty pocket').
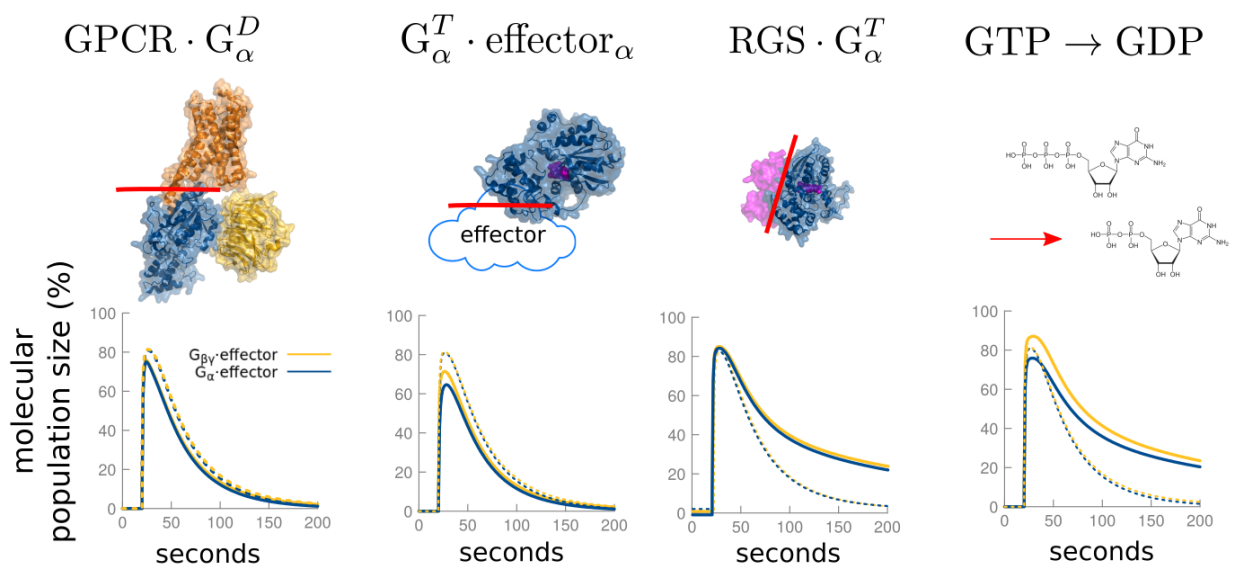

"empty pocket"

Figure 2: Mutations in different locations on the protein change signal in different ways and respond to different pharmacological intervention. Qualitative change in the signal shape upon reaction rates modified through mutations. The mutations are taken to degrade (slow down) each interaction. Exact amount of change depends on the actual mutation and precise values of wild-type reaction constants. The corresponding response to treatment is summarized in Table 1. 


\section{Discussion}

\section{Mutations in GNAO1 cause change in reaction rates}

According to our current knowledge of the mode of interaction of G $\alpha$ proteins, there are five major functionally active regions in G $\alpha$ : the catalytic pocket and interfaces with G $\beta \gamma$, GPCR, RGS, and the effector (Fig. 3). The catalytic pocket can further be divided into nucleotide, ion, and the phosphate binding sites. As a rule of thumb, the closer the mutation to each one of these regions, the stronger the impact on the interaction. In particular, the mutations that disable the ion $\left(\mathrm{Mg}^{+2}\right)$ binding change the ability of $\mathrm{G} \alpha$ to bind nucleotide by an order of magnitude [12].

A qualitatively different effect is created by mutations within the catalytic pocket that, either through changing the electrostatic properties of the catalytic pocket or by causing steric hindrance (spatial blocking), completely abolish the nucleotide binding. These mutations create empty pocket species of $\mathrm{G} \alpha$, which is never seen in the wild type, except perhaps as a brief transitional state. The mutant proteins do not bind $\mathrm{G} \beta \gamma$, and instead interact strongly with the GPCR irrespective of its activation state, thus effectively sequestering a fraction of the population of GPCRs from the system [35-37], and at the same time, presumably, producing population of free $\mathrm{G} \beta \gamma$ units, which is not normally seen in the equilibrium state of the cell. The ability of the cell to resolve the excess G $\beta \gamma$ in this context requires further investigation [43].

\section{Change in reaction rates modifies the shape of the GPCR-GNAO1 signal}

We have argued (Fig. 2) that there are three major ways in which the wild-type GPCR signal can be distorted: The signal, either $\mathrm{G} \alpha$ or $\mathrm{G} \beta \gamma$ or both, can be reduced in intensity through changed rates for GNAO1/GPCR or GNAO1/effector reactions. It may not decay as fast as in the wild-type if the catalytic pocket is modified, thus changing the rate of GTP to GDP conversion. A similar effect can be achieved my modifying the rate of RGS binding. Finally, the signal may have a baseline presence and/or propensity to spike past the threshold, if the nucleotide binding is completely abolished.

\section{Signal distortion manifests as phenotype and reaction to treatment}

By comparison with reported phenotypes (below), we observe that reduction in G $\alpha$ signal often coincides with MD, and spiking or slow withdrawal of the G $\beta$ signal with E phenotype. Also, he type of distortion in the signal between neurons should be reflected in the response to treatment. For example, we expect that the signal reduced through weakened interaction with receptor can be rescued by the increased level of agonist. As far as the rest of the system is concerned, the precise etiology of the distortion does not matter. That is, mutations in different locations on the protein can manifest themselves as the same or similar phenotype (with the direct comparison of phenotype in different individuals often not being feasible). Conversely, mutations in the same structural location but involving different amino acid types may result in different size or shape of the signal distortion, and thus different phenotypes (see SI, Table 2S, R209C and R209H mutations for an example). The development of symptoms may take different time course in different individuals [44]. In the discussion below we refer to the phenotype present at the same time as the reported treatment.

\section{Structural map of disease variants and responses to treatment}

To test the predictive capability of our signaling model, we compiled the response to treatment reported so far for GNAO1 patients (SI, Table 2). Several mutational hot-spots on the protein structure result in effects that can be rationalized, and have been reported to respond to comparable treatment 

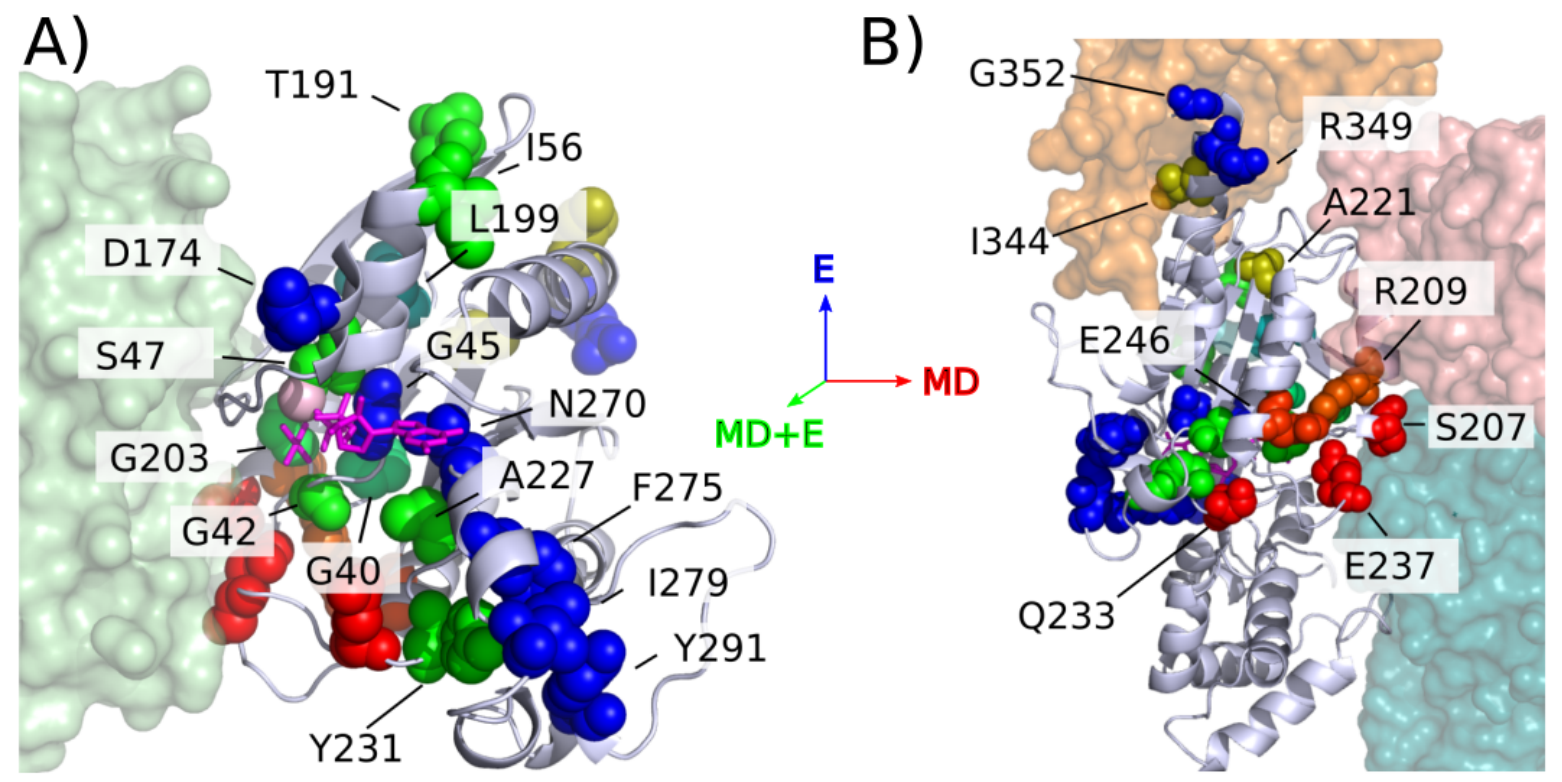

Figure 3: Structural map of disease-related variants in GNAO1. Cartoon representation, white: GNAO1 protein backbone. Orange, surface representation: GPCR. Red and green surface representation: two possible positions of adenylate cyclase, GNAO1 effector (red: crystallographic from [45]; green: hypothetical from [46]). Pale green: RGS. Sphere representation: position of missense variants (SI, Table 2). Red: movement disorder (MD), blue: epilepsy (E), green: both phenotypes. Cases when different phenotype combinations were reported in different patients or at different points in development are indicated by the combination of the basic RGB colors (SI, Fig. S11). A) View from the catalytic pocket side; pink: Mg ion; magenta sticks: nucleotide. B) View from the back side of the catalytic pocket - putative region of interaction with the effector.

\section{Variants leading to epilepsy ( $E$ and $M D+E)$, Fig. 3A}

When mapped on the structure, the most striking feature of the variants reported so far is that the variants placed close to the catalytic pocket usually result in epilepsy, with or without a concomitant movement disorder. The mutations which lead to change in geometry of the catalytic pocket, but can still accommodate the nucleotide lead to weakened enzymatic activity, and prolonged signal Fig. 2, $\mathrm{GTP} \rightarrow \mathrm{GDP}$. Good candidates for this effect are G40E, and L199P, reported to respond to reduction in neurotransmitter release [44] and neuronal excitability [6]. However, if the nucleotide binding is abolished, as is the case with large replacements in catalytic pocket, disrupted binding of the catalytic ion S47G [9], or a major structural change (G203R [1]), a baseline G $\beta \gamma$ signal may appear, accompanied by weakened G $\alpha$ signaling Fig. 2, 'empty pocket'. The former agrees with the patients generally reacting to enhancers of GABAergic signaling $[1,44,47,48]$, while the weakened $\mathrm{G} \alpha$ signaling branch reacts to reduced dopamine availability [9] (see discussion of MD variants below).

\section{Movement disorder-related (MD) variants, Fig. 3B}

Variants resulting in MD-only phenotype cluster in two regions of the GNAO1 protein: the C-terminal helix through which the protein interacts with GPCR, and the "backside" of the catalytic pocket (red in Fig. 3). What they have in common is substantial distance from the catalytic pocket. However, some cases in this region have mixed, or even E-only phenotype (SI, Table S2). The mutations leading to the weakened interaction with the GPCR (Fig. 2, GPCR.G $G_{\alpha}^{D}$ ), can be counterbalanced by the increased 
Table 1: Main features of effective treatment for variants with interpretable mechanism of impact. NT: neurotransmitter. NE: neuronal excitability. MD cluster: see text and Fig.3.

\begin{tabular}{|l|l|l|}
\hline Region & effect & Effective treatment, main features \\
\hline C-terminal & GPCR interaction $\downarrow$ & dopamine $\uparrow$ \\
catalytic pocket & catalysis $\downarrow$ & NT release $\downarrow$ NE $\downarrow$ \\
catalytic pocket & 'empty pocket' & GABA $\uparrow$ dopamine $\downarrow$ \\
MD cluster & $?$ & dopamine $\downarrow$ GABA $\uparrow$ \\
\hline
\end{tabular}

level of the agonist in the simulation (SI, Fig. S7). In [44] we report three cases with mutations in this region consistent with weakened interaction. All of these showed MD phenotype, one of them without any epileptic symptoms. All three responded well to increased availability of dopamine. (In this discussion, however, we cannot rule out the possibility that dopamine leads to improvement via a GNAO1-independent mechanism.)

The other group of mutations leading to predominantly MD phenotype ('MD cluster') appears in the region that partially but not completely overlaps with RGS and putative AC binding sites (SI, Fig. S9). A particular feature of this group is that even though by their location they would seem to exert their effect through degraded interaction with the effector or RGS, their response to treatment resembles more closely that of the empty pocket mutations (Table 1; SI Table S2.). The phenotype in the region is much more stratified than in the other regions. The pair R209-E246 forms a salt bridge [49], an electrostatic configuration of a positively and negatively charged residue that stabilizes the structure. It has been repeatedly reported as a source of GNAO1 phenotypes, R209C as MD+E $[8,9,44,50], \mathrm{R} 209 \mathrm{H}$ as MD only [7, 51-53]. Even though the substitution is conservative, R209H appears particularly difficult to treat, with the reported results often referring to ICU treatment (SI, Table S2). E346K has so far been associated with MD-only [7, 8, 50], responsive to reduction in dopamine availability and increased GABA-ergic activity. Its response to treatment is reminiscent of the variants leading plausibly to empty pocket mutant (Table 1), with a stunted $\mathrm{G} \alpha$, and baseline $\mathrm{G} \beta \gamma$ signal. The former is a rather puzzling possibility for $\mathrm{E} 246 \mathrm{~K}$, since this mutation produces minor effect on the interaction with AC [54], commonly associated with MD phenotypes, thus it is not clear where this reduction in the signal strength is created. This behavior could be explained if the mutation makes binding of $\mathrm{G} \alpha$ to an unspecified (and GPCR-unrelated) partner competitive with binding to AC. This interaction would sequester $\mathrm{G} \alpha$ from inhibiting $\mathrm{AC}$ function, as is the case for the empty pocket mutants Fig. 2, albeit by a different mechanism. The unproductive coupling would sequester the $\mathrm{G} \alpha$; however, with the interaction between $\mathrm{G} \alpha$ and $\mathrm{G} \beta \gamma$ still functional, in contrast to the empty pocket case, no G $\beta \gamma$-related epileptic spikes in the signal would occur. The variants resulting in E237K, E246K, and E246 have been explicitly reported not to react to increased level of dopamine [8, 48]. It is unclear at this point why these cases react to dopamine depletion, but the negative pre-synaptic feedback role of D2Ls should be kept in mind as a possibility.

\section{'Cryptic' variants}

For some variants, resulting in mutations away from any known functional regions on the protein, we cannot provide a convincing model of action. The examples include the small cluster of mutations, F275S [55] and I279N [1] where mutations impact a structurally disordered loop, close to the surface and away from any interfaces and from the catalytic site. They all result in E phenotype, perhaps accompanied by hypotonia, but no clear movement disorder. The hope is that these will be included in the extended model, when the related properties of GNAO1 protein become known. Furthermore, in some cases it is difficult to rationalize the phenotype, the matter possibly complicated by the uncertainty in the assignment of the disease causing variant (SI, 'Forme fruste'). 


\section{Conclusion: rational dissection of genotype/phenotype relations in GNAO1 mutants, and the implications for the treatment options}

Based on our current understanding of the interactions that GNAO1 engages in and the reported phenotypes it causes, four salient points emerge:

1) Mutations weakening the interaction with the GPCR have been reported to result either in movement disorders (MD), epilepsy (E), or both. The patients have been reported to react well to increased availability of dopamine, which we hypothesize is capable of overcoming the weak baseline GPCR-GNAO1 interaction.

2) Mutations abolishing the binding of nucleotide in the G $\alpha$ catalytic pocket ('empty pocket' mutants) should particularly strongly sensitize the carriers to over-the-threshold spikes, though this conclusion is a subject of further investigation into how the cell copes with excess free G $\beta \gamma$ that should appear in that case. In this case the effects on $\mathrm{G} \beta \gamma$ and $\mathrm{G} \alpha$ are opposite: the spike in $\mathrm{G} \beta \gamma$, responsive to a GABA receptor stimulants, is accompanied by a weakened $\mathrm{G} \alpha$, responsive to reduced dopamine availability.

3) Mutations in the MD cluster are the only ones that can result in pure MD. (Though the converse is not true: in some patients the mutations in the same region can result in pure E.) The function of the region is not clear. The patients have been reported to react favorably to combined therapy of reduced dopamine availability and enhanced GABAeric signaling, similar to reported effective therapy for empty pocket mutants.

4) Mutations close to the catalytic pocket and/or close to the interface with RGS result in the signal that does not withdraw properly. They always result in E phenotype, with or without MD. Overall, the patients with these variants seem to react to lowering neuronal excitability, though no single therapeutic approach emerged so far as optimal.

The main effects generated at the molecular level are increase/decrease in the signal intensity, or its improper dampening. These effects can be generated at several points on the protein structure and through different mechanisms; however, the rest of the molecular and even cellular system may find them indistinguishable, and they will react to a comparable treatment. In addition to motivating further study of this system, the full complexity of which we have not even begun to discuss (such as the effect of sex differences or brain development on the exhibited phenotype) it was our intent to point to a way of reasoning that will eventually lead to development of more specific therapy and its application tailored to particular variant(s) seen in the patient.

\section{Materials and methods}

\section{GNA01 splice}

All mutations discussed in this work refer to GNAO1 splice most commonly expressed in the brain, NCBI accession number NM_020988.2.

\section{Molecular structures - modeling and visualization}

The model for active GNAO1 protein structure was build on the template from PDB [56] identifier 3C7K [49], using Swissmodel [57]. The same PDB entry was used to model the interaction between G $\alpha$ and an RGS domain. The interaction with GPCR modeled after PDB entry 3sn6 [58], and interaction with acetylcholinesterase after 1azs [45], and theoretical model by van Keulen and Rothlisberger [46, 59] Mapping between various complex structures was done using deconStruct [60]. The illustrations were generated using PyMol [61]. 


\section{Modeling GPCR-G signal}

The set of equations describing the core GPCR signaling cycle (SI, Fig S1) was solved using BioNetGen 2.2 [62]. The input for BioNetGen was prepared using V-Cell [63]. The parametrization was taken from the published biochemical experiments[34-36, 64], details: SI, Fig S1. The values used for modified interaction rates, Fig. 2 can be found in SI, Fig. S4.

\section{References}

[1] Nakamura K, Kodera H, Akita T, Shiina M, Kato M, et al. (2013) De novo mutations in gnao1, encoding a g $\alpha$ o subunit of heterotrimeric g proteins, cause epileptic encephalopathy. The American Journal of Human Genetics 93: 496-505.

[2] Gawlinski P, Posmyk R, Gambin T, Sielicka D, Chorazy M, et al. (2016) Peho syndrome may represent phenotypic expansion at the severe end of the early-onset encephalopathies. Pediatric neurology 60: 83-87.

[3] Law CY, Chang STL, Cho SY, Yau EKC, Ng GSF, et al. (2015) Clinical whole-exome sequencing reveals a novel missense pathogenic variant of gnao1 in a patient with infantile-onset epilepsy. Clinica Chimica Acta 451: 292-296.

[4] Marcé-Grau A, Dalton J, López-Pisón J, García-Jiménez MC, Monge-Galindo L, et al. (2016) Gnao1 encephalopathy: further delineation of a severe neurodevelopmental syndrome affecting females. Orphanet journal of rare diseases 11: 38.

[5] Yilmaz S, Turhan T, Ceylaner S, Gökben S, Tekgul H, et al. (2016) Excellent response to deep brain stimulation in a young girl with gnao1-related progressive choreoathetosis. Child's Nervous System 32: 1567-1568.

[6] Talvik I, Møller RS, Vaher M, Vaher U, Larsen LH, et al. (2015) Clinical phenotype of de novo gnao1 mutation: case report and review of literature. Child Neurology Open 2.

[7] Ananth AL, Robichaux-Viehoever A, Kim YM, Hanson-Kahn A, Cox R, et al. (2016) Clinical course of six children with gnao1 mutations causing a severe and distinctive movement disorder. Pediatric neurology 59: 81-84.

[8] Waak M, Mohammad SS, Coman D, Sinclair K, Copeland L, et al. (2017) Gnao1-related movement disorder with life-threatening exacerbations: movement phenomenology and response to dbs. J Neurol Neurosurg Psychiatry : jnnp-2017.

[9] Danti FR, Galosi S, Romani M, Montomoli M, Carss KJ, et al. (2017) Gnao1 encephalopathy broadening the phenotype and evaluating treatment and outcome. Neurology Genetics 3: e143.

[10] Jiang M, Bajpayee NS (2009) Molecular mechanisms of go signaling. Neurosignals 17: 23-41.

[11] Scheffzek K, Ahmadian MR (2005) Gtpase activating proteins: structural and functional insights 18 years after discovery. Cellular and Molecular Life Sciences CMLS 62: 3014-3038.

[12] Higashijima T, Ferguson K, Sternweis P, Smigel MD, Gilman AG (1987) Effects of mg2+ and the beta gamma-subunit complex on the interactions of guanine nucleotides with g proteins. Journal of Biological Chemistry 262: 762-766.

[13] Clapham DE, Neer EJ (1997) G protein $\beta \gamma$ subunits. Annual review of pharmacology and toxicology 37: 167-203.

[14] Wettschureck N, Offermanns S (2005) Mammalian g proteins and their cell type specific functions. Physiological reviews 85: 1159-1204. 
[15] Garcia-Higuera I, Thomas TC, Yi F, Neer EJ (1996) Intersubunit surfaces in g protein heterotrimers analysis by cross-linking and mutagenesis of $\beta$. Journal of Biological Chemistry 271: $528-535$.

[16] Bastian F, Parmentier G, Roux J, Moretti S, Laudet V, et al. (2008) Bgee: integrating and comparing heterogeneous transcriptome data among species. In: Data Integration in the Life Sciences. Springer, pp. 124-131.

[17] Gray KA, Yates B, Seal RL, Wright MW, Bruford EA (2014) Genenames. org: the hgnc resources in 2015. Nucleic acids research 43: D1079-D1085.

[18] Petrovski S, Küry S, Myers CT, Anyane-Yeboa K, Cogné B, et al. (2016) Germline de novo mutations in gnb1 cause severe neurodevelopmental disability, hypotonia, and seizures. The American Journal of Human Genetics 98: 1001-1010.

[19] De Mei C, Ramos M, Iitaka C, Borrelli E (2009) Getting specialized: presynaptic and postsynaptic dopamine d2 receptors. Current opinion in pharmacology 9: 53-58.

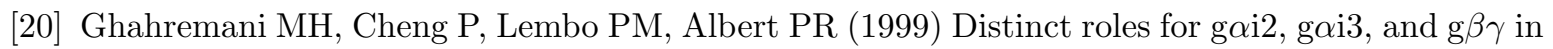
modulation of forskolin-or gs-mediated camp accumulation and calcium mobilization by dopamine d2s receptors. Journal of Biological Chemistry 274: 9238-9245.

[21] Raskind WH, Friedman JR, Roze E, Méneret A, Chen DH, et al. (2017) Adcy5-related dyskinesia: Comments on characteristic manifestations and variant-associated severity. Movement Disorders 32: 305-306.

[22] Carecchio M, Mencacci NE, Iodice A, Pons R, Panteghini C, et al. (2017) Adcy5-related movement disorders: Frequency, disease course and phenotypic variability in a cohort of paediatric patients. Parkinsonism \& Related Disorders .

[23] Sprang SR, Chen Z, Du X (2007) Structural basis of effector regulation and signal termination in heterotrimeric g $\alpha$ proteins. Advances in protein chemistry 74: 1-65.

[24] Macdonald R, Gallagher M (2014) The genetic epilepsies. In: Rosenberg's Molecular and Genetic Basis of Neurological and Psychiatric Disease, Elsevier, chapter 84.

[25] Villa C, Combi R (2016) Potassium channels and human epileptic phenotypes: An updated overview. Frontiers in cellular neuroscience 10.

[26] Krapivinsky G, Kennedy ME, Nemec J, Medina I, Krapivinsky L, et al. (1998) G $\beta \gamma$ binding to girk4 subunit is critical for $g$ protein-gated $\mathrm{k}+$ channel activation. Journal of Biological Chemistry 273: $16946-16952$.

[27] Ostrom RS, Post SR, Insel PA (2000) Stoichiometry and compartmentation in g protein-coupled receptor signaling: implications for therapeutic interventions involving gs. Journal of Pharmacology and Experimental Therapeutics 294: 407-412.

[28] Guo W, Shi L, Filizola M, Weinstein H, Javitch JA (2005) Crosstalk in g protein-coupled receptors: changes at the transmembrane homodimer interface determine activation. Proceedings of the National Academy of Sciences of the United States of America 102: 17495-17500.

[29] Milligan G (2007) G protein-coupled receptor dimerisation: molecular basis and relevance to function. Biochimica et Biophysica Acta (BBA)-Biomembranes 1768: 825-835.

[30] Navarro G, Cordomí A, Zelman-Femiak M, Brugarolas M, Moreno E, et al. (2016) Quaternary structure of a g-protein-coupled receptor heterotetramer in complex with $\mathrm{g}$ i and g s. BMC biology 14: 26 . 
[31] Javitch JA (2004) The ants go marching two by two: oligomeric structure of g-protein-coupled receptors. Molecular pharmacology 66: 1077-1082.

[32] Nobles M, Benians A, Tinker A (2005) Heterotrimeric g proteins precouple with g protein-coupled receptors in living cells. Proceedings of the National Academy of Sciences of the United States of America 102: 18706-18711.

[33] Traut TW (1994) Physiological concentrations of purines and pyrimidines. Molecular and cellular biochemistry 140: 1-22.

[34] Zhong H, Wade SM, Woolf PJ, Linderman JJ, Traynor JR, et al. (2003) A spatial focusing model for g protein signals. Journal of Biological Chemistry 278: 7278-7284.

[35] Yu B, Slepak VZ, Simon MI (1997) Characterization of a go $\alpha$ mutant that binds xanthine nucleotides. Journal of Biological Chemistry 272: 18015-18019.

[36] Yu B, Simon MI (1998) Interaction of the xanthine nucleotide binding go $\alpha$ mutant with g proteincoupled receptors. Journal of Biological Chemistry 273: 30183-30188.

[37] Yu B, Gu L, Simon MI (2000) Inhibition of subsets of g protein-coupled receptors by empty mutants of g protein $\alpha$ subunits in go, g11, and g16. Journal of Biological Chemistry 275: 71-76.

[38] Resat H, Petzold L, Pettigrew MF (2009) Kinetic modeling of biological systems. Computational Systems Biology : 311-335.

[39] Lodish H, Berk A, Zipursky SL, Matsudaira P, Baltimore D, et al. (2000) Neurotransmitters, synapses, and impulse transmission, WH Freeman.

[40] Yamada M, Inanobe A, Kurachi Y (1998) G protein regulation of potassium ion channels. Pharmacological reviews 50: 723-757.

[41] Holt JC, Jordan PM, Lysakowski A, Shah A, Barsz K, et al. (2017) Muscarinic acetylcholine receptors and $\mathrm{m}$-currents underlie efferent-mediated slow excitation in calyx-bearing vestibular afferents. Journal of Neuroscience 37: 1873-1887.

[42] Purves D, Augustine G, Fitzpatrick D, Katz L, Lamantia AS, et al. (2001) Neurotransmitter Release and Removal, Sinauer Associates.

[43] Jiang M, Gold MS, Boulay G, Spicher K, Peyton M, et al. (1998) Multiple neurological abnormalities in mice deficient in the g protein go. Proceedings of the National Academy of Sciences 95: $3269-3274$.

[44] Kelly, McKenna and GNAO1 Phenotyping Working Group (2018) Expanded spectrum of neurodevelopmental disease associated with variants affecting the GNAO1 GTP-binding region. in preparation .

[45] Tesmer JJ, Sunahara RK, Gilman AG, Sprang SR (1997) Crystal structure of the catalytic domains of adenylyl cyclase in a complex with gs $\alpha \cdot$ gtp $\gamma$ s. Science 278: 1907-1916.

[46] Van Keulen SC, Rothlisberger U (2017) Exploring the inhibition mechanism of adenylyl cyclase type 5 by n-terminal myristoylated gai1. PLoS computational biology 13: e1005673.

[47] Galanopoulou AS (2008) Gabaa receptors in normal development and seizures: friends or foes? Current neuropharmacology 6: 1-20.

[48] Schorling DC, Dietel T, Evers C, Hinderhofer K, Korinthenberg R, et al. (2017) Expanding phenotype of de novo mutations in gnao1: four new cases and review of literature. Neuropediatrics 48: $371-377$. 
[49] Slep KC, Kercher MA, Wieland T, Chen CK, Simon MI, et al. (2008) Molecular architecture of g $\alpha \mathrm{o}$ and the structural basis for rgs16-mediated deactivation. Proceedings of the National Academy of Sciences 105: 6243-6248.

[50] Saitsu H, Fukai R, Ben-Zeev B, Sakai Y, Mimaki M, et al. (2016) Phenotypic spectrum of gnao1 variants: epileptic encephalopathy to involuntary movements with severe developmental delay. European Journal of Human Genetics 24: 129-134.

[51] Menke LA, Engelen M, Alders M, Odekerken VJ, Baas F, et al. (2016) Recurrent gnao1 mutations associated with developmental delay and a movement disorder. Journal of child neurology 31: $1598-1601$.

[52] Dhamija R, Mink JW, Shah BB, Goodkin HP (2016) Gnao1-associated movement disorder. Movement Disorders Clinical Practice 3: 615-617.

[53] Kulkarni N, Tang S, Bhardwaj R, Bernes S, Grebe TA (2016) Progressive movement disorder in brothers carrying a gnao1 mutation responsive to deep brain stimulation. Journal of child neurology 31: 211-214.

[54] Feng H, Sjögren B, Karaj B, Shaw V, Gezer A, et al. (2017) Movement disorder in gnao1 encephalopathy associated with gain-of-function mutations. Neurology 89: 762-770.

[55] Phenome E, Consortium ER, Consortium E, et al. (2014) De novo mutations in synaptic transmission genes including dnm1 cause epileptic encephalopathies. The American Journal of Human Genetics 95: 360-370.

[56] Berman HM, Westbrook J, Feng Z, Gilliland G, Bhat TN, et al. (2000) The protein data bank. Nucleic acids research 28: 235-242.

[57] Biasini M, Bienert S, Waterhouse A, Arnold K, Studer G, et al. (2014) Swiss-model: modelling protein tertiary and quaternary structure using evolutionary information. Nucleic acids research 42: W252-W258.

[58] Rasmussen SG, DeVree BT, Zou Y, Kruse AC, Chung KY, et al. (2011) Crystal structure of the $\beta 2$ adrenergic receptor-gs protein complex. Nature 477: 549 .

[59] Van Keulen SC, Rothlisberger U (2016) Effect of n-terminal myristoylation on the active conformation of g $\alpha$ i 1-gtp. Biochemistry 56: 271-280.

[60] Zhang ZH, Lee HK, Mihalek I (2010) Reduced representation of protein structure: implications on efficiency and scope of detection of structural similarity. BMC bioinformatics 11: 155 .

[61] DeLano W (2002). The pymol molecular graphics system.

[62] Harris LA, Hogg JS, Tapia JJ, Sekar JA, Gupta S, et al. (2016) Bionetgen 2.2: advances in rule-based modeling. Bioinformatics 32: 3366-3368.

[63] Schaff JC, Vasilescu D, Moraru II, Loew LM, Blinov ML (2016) Rule-based modeling with virtual cell. Bioinformatics 32: 2880-2882.

[64] Calebiro D, Nikolaev VO, Gagliani MC, de Filippis T, Dees C, et al. (2009) Persistent cAMPsignals triggered by internalized G-protein-coupled receptors. PLoS biology 7: e1000172. 


\title{
Molecular map of GNAO1-related disease phenotypes and reactions to treatment
}

\author{
Supplementary Information
}

Ivana Mihalek, Meredith Park, McKenna Kelly, Jeff L. Waugh, Annapurna Poduri, and Olaf Bodamer

Boston Children's Hospital, Harvard Medical School, MA, USA

December 10, 2017 


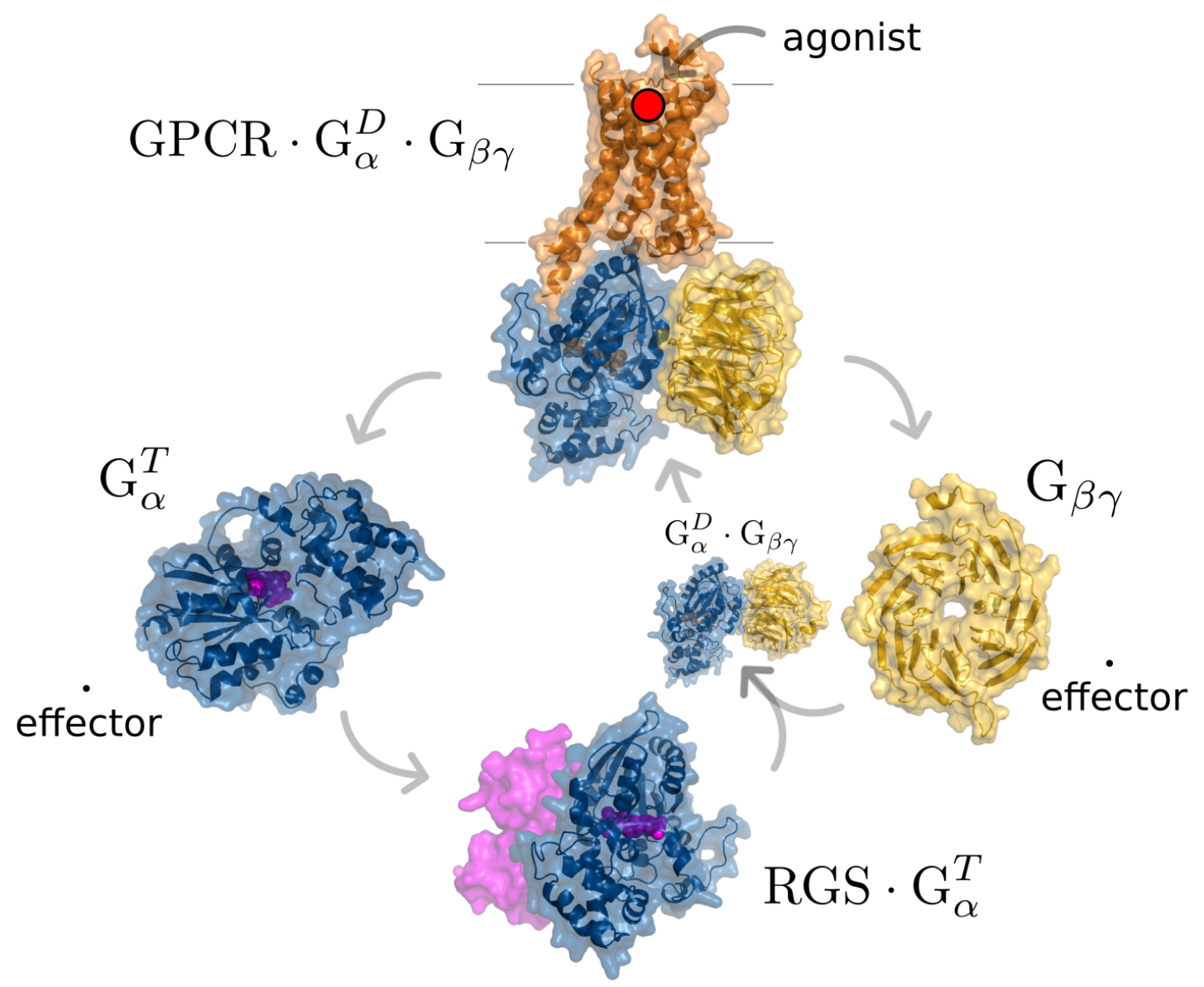

Figure S1: Schematic representation of the activated GPCR system. See Introduction in the main text for the molecular name acronyms. Dots indicate a molecular complex. Superscript $D / T$ : bound GDP/GTP. After binding to activated GPCR, G trimer dissociates - from GPCR and into activated, GTP bound, G $\alpha$ (blue; GTP indicated in pink) and G $\beta \gamma$ (yellow). Both units immediately associate with their effectors. GTP-bound $\mathrm{G} \alpha$ dissociates with some small probability from its effector, allowing it to interact with RGS. RGS speeds up the GTP hydrolysis, and now GDP-bound $\mathrm{G}_{\alpha}$ becomes the preferred interaction partner for $\mathrm{G} \beta \gamma$, and the trimer re-forms. The fraction of time that $\mathrm{G} \alpha$ and $\mathrm{G} \beta \gamma$ spend interacting with their effectors depends on the ratio of association/dissociation rates for each interaction. The same is true for the time it takes for the system to return to its original, G trimer-only state, once the agonist is removed. 


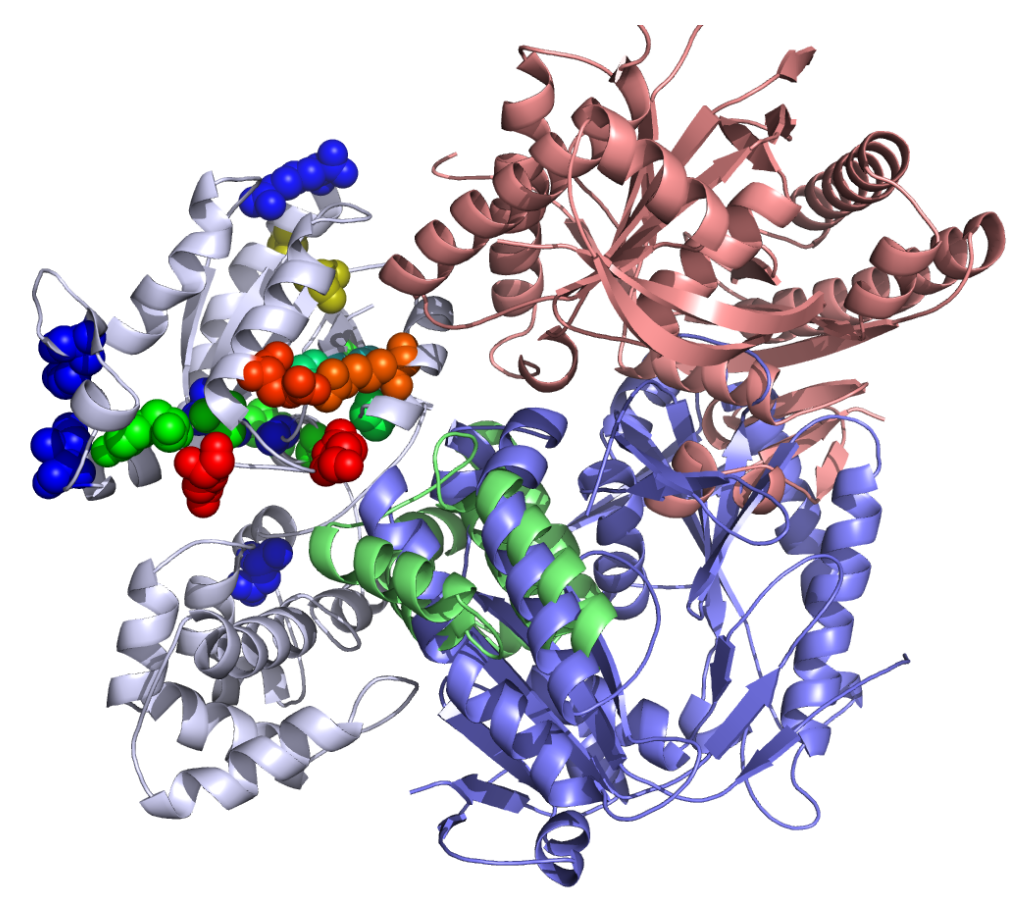

Figure S2. Competitive binding between RGS and effectors. Despite evidence that RGS (green cartoon representation) might be competing [1] with the effector for binding with G $\alpha$ (white cartoon), the crystal structures of RGS domain bound to $\mathrm{G} \alpha$ (PDB identifier $3 \mathrm{c} 7 \mathrm{k}$, [2]), and $\mathrm{G}_{\alpha s}$ interacting with adenylate cyclase (1azs [3]; maroon), show the noncompeting conformation. And again, the mode of interaction proposed by van Keulen and Rothlisberger $([4,5]$; blue $)$ does show the competing interaction site. In the simulated system used in the text, we take that the interaction is competitive, and happens sequentially, that is, the GTP-bound G $\alpha$ must dissociate from the effector to be able to interact with RGS. 
bioRxiv preprint doi: https://doi.org/10.1101/232058; this version posted December 11, 2017. The copyright holder for this preprint (which was not certified by peer review) is the author/funder. All rights reserved. No reuse allowed without permission.

Figure S3. Independence of the signal distortion on the ratio of GPCR components in the core signaling cycle. 


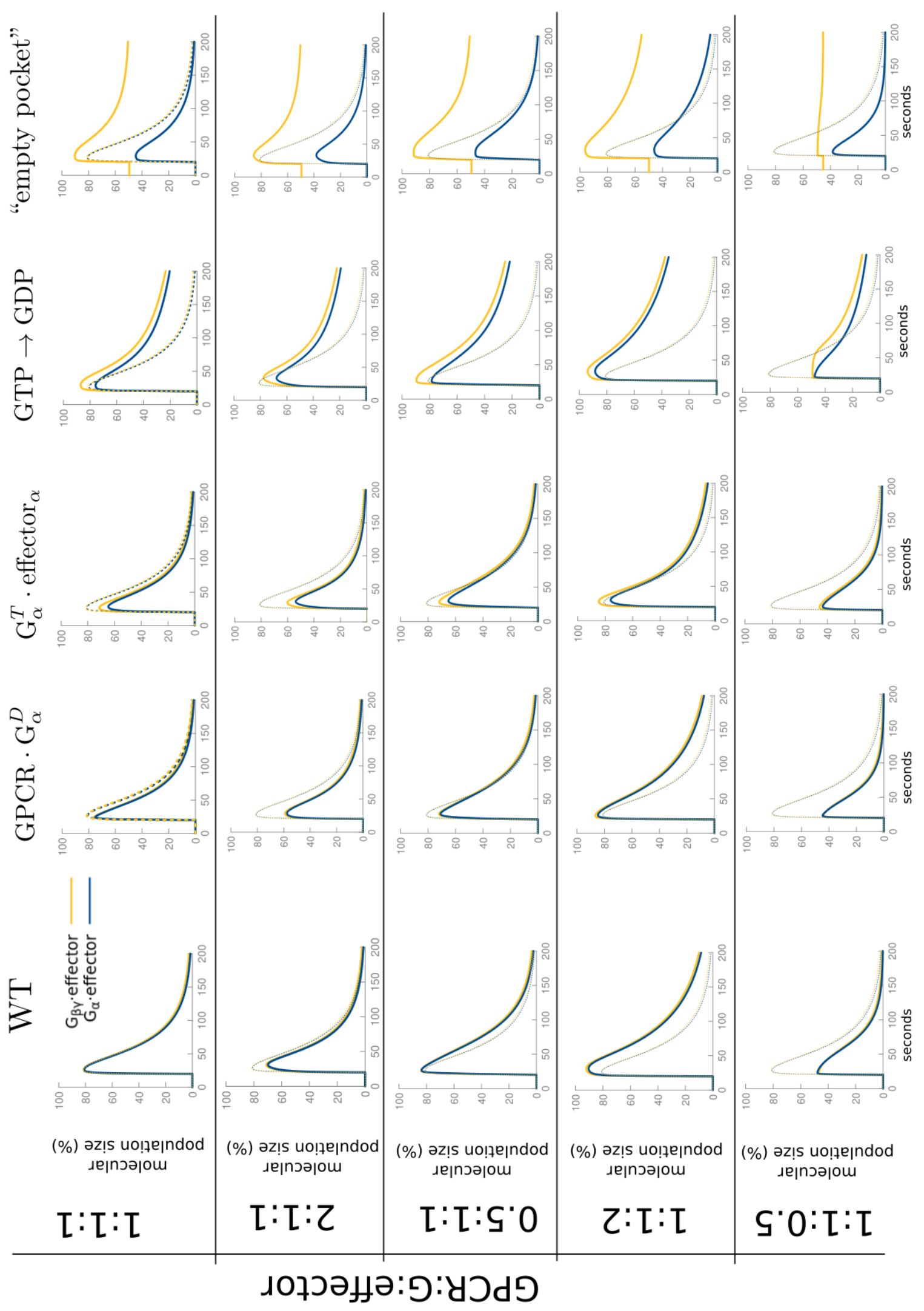


Figure S4: GPCR reaction cycle - parametrization for the wild type system. Diseaserelated mutations modify these numbers. In the main text we use modified values (see also Fig. S6) to learn how the system reacts to the mutation-induced changes.

G: G-protein. GPCR: G-protein coupled receptor. RGS: regulator of G -signaling STA: signal terminating agent. Superscript indicates binding of small ligands: $D$ stands for GDP, $T$ for GTP, and $A$ for generic agonist. Subscripts: subunits of G-protein trimer. Units for the indicated reaction rates: $s^{-1}$ for the first order, and $(\mu M s)^{-1}$ for the second order reactions.

The numbers in the brackets refer to the sources of parameter values:

(1) STA can stand for either acetylcholinesterase in the case of acetylcholine signaling, or GAT proteins in the case of GABA-ergic signaling. In either case, the reaction rates were set arbitrarily, in order to model the narrow input signal. In all cases $\mathrm{Mg}+$ ions are assumed to be present and bound to the $\mathrm{G} \alpha$ in its catalytic pocket.

(2) Parameters for biding of the agonist and G $\alpha$ to GPCR, as well as for G-trimer formation taken from (6)

(3) Parameters for dissociation of receptor from $\mathrm{G}_{\alpha}^{T}$ complex, for RGS binding, and for GTP hydrolysis from (7).

(4) From experiments of Yu and Simon (8), we take that the mutants that do not bind GTP or GDP (such as $\mathrm{G}_{o} \alpha \mathrm{D} 273 \mathrm{~N}$ reported therein) can bind the receptor in the absence of $\mathrm{G} \beta \gamma$ and the agonist, but are never (or rarely) released.

The kinetic constants for the interaction between the receptor and the empty mutant or its surrogate $\mathrm{G}_{o} \alpha \mathrm{X}$ (a double mutant GNAO1 regulated by Xanthine nucleotide), were not explicitly reported in this work. However, from the overall similarity to behavior of G-protein heterotrimer that includes GNAO1, we took the assumption that the forward binding rates to GPCR are comparable to wild-type GNAO1. The same lab also reported that $\mathrm{G}_{o} \alpha \mathrm{X}$, will not bind $\mathrm{G} \beta \gamma$ in the absence of XDP, xanthine diphosphate (9), and we thus also take that the impaired nucleotide binding implies impaired binding of $\mathrm{G} \beta \gamma$ in any $\mathrm{G}_{o} \alpha$ mutant. 


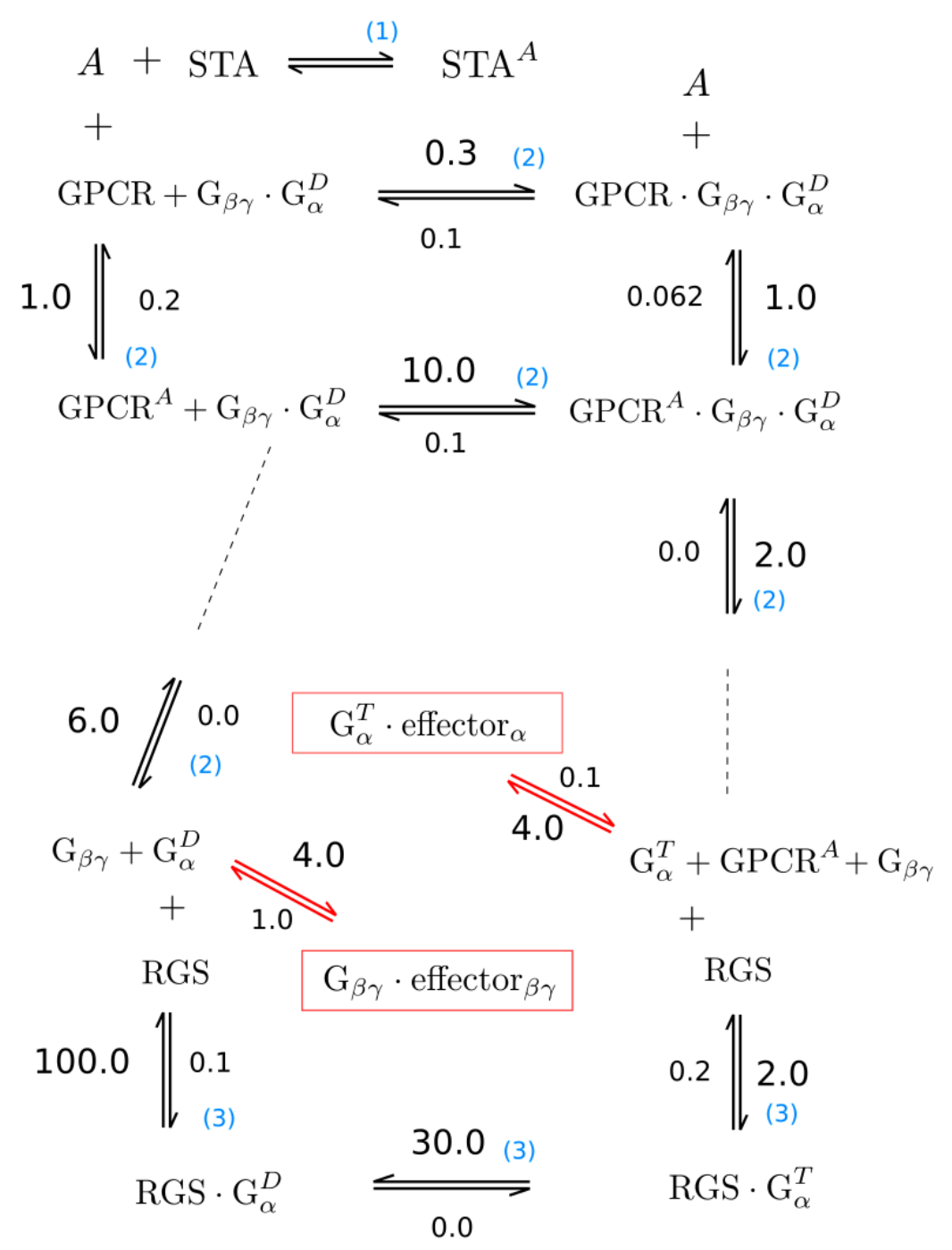

$$
\mathrm{GPCR}+\mathrm{G}_{\alpha}^{0} \stackrel{1.0 \stackrel{(6)}{\rightleftharpoons}}{\stackrel{1.0}{\rightleftharpoons}} \mathrm{GPCR} \cdot \mathrm{G}_{\alpha}^{0}
$$




\begin{tabular}{|l|r|}
\hline \multicolumn{2}{|c|}{ Concentration $(\mu \mathrm{M})$} \\
\hline $\mathrm{G}_{\alpha}$, wild-type & 25 \\
$\mathrm{G}_{\alpha}$, mutant & 25 \\
$\mathrm{GPCR}$ & 50 \\
$\mathrm{G} \beta \gamma$ & 50 \\
$\mathrm{RGS}$ & 30 \\
$\mathrm{G}_{\alpha}$ effector & 50 \\
$\mathrm{G} \beta \gamma$ effector & 50 \\
agonist & $60 @ 20.0 \mathrm{~s}$ \\
signal terminating agent & $120 @ 20.1 \mathrm{~s}$ \\
\hline
\end{tabular}

Table S1. Default concentrations used in GPCR cycle calculation. For the agonist and the signal terminating agent the time when they appear in the simulation is also indicated. Signal terminating agent (STE) is a generic device to return the system to its equilibrium distribution of molecular species. The agonist/STE pair can be, for example, acetylcholine and acetylcholinesterase. 
A)

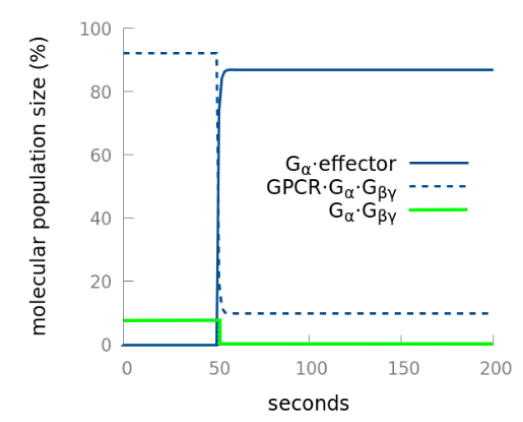

B)

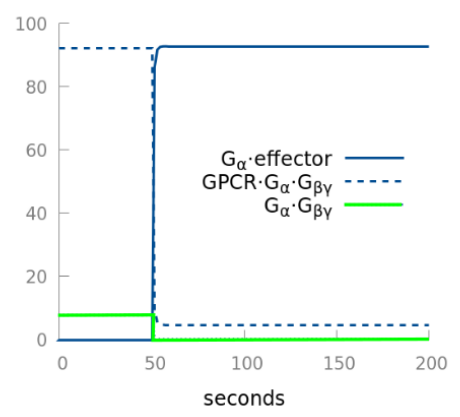

C)

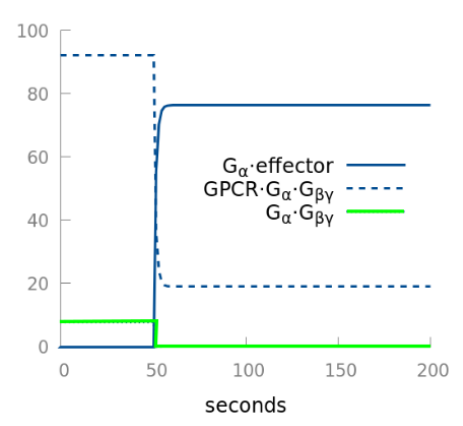

Figure S5. Changing reaction parameters re-partitions the molecular population of GPCR- and effector-bound G $\alpha$. Panel A) the parametrization used in the text (Fig. S1). B) doubling the rate for GDP/GTP exchange, and halving the release rate of $\mathrm{G} \alpha$ from effector moves more G $\alpha$ to effector bound state. C) In the opposite case - halving the GDP/GTP exchange rate, and doubling the rate of release of $\mathrm{G} \alpha$ from effector moves more $\mathrm{G} \alpha$ into GPCR bound trimer population. 
A)

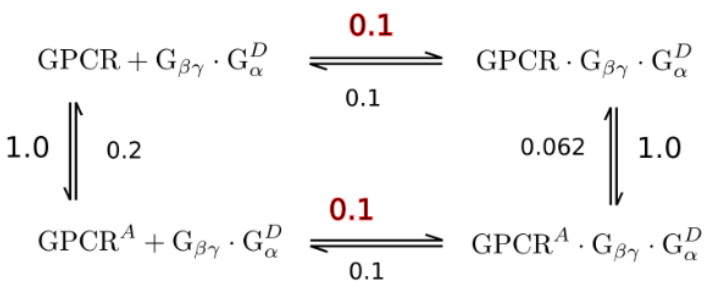

B)

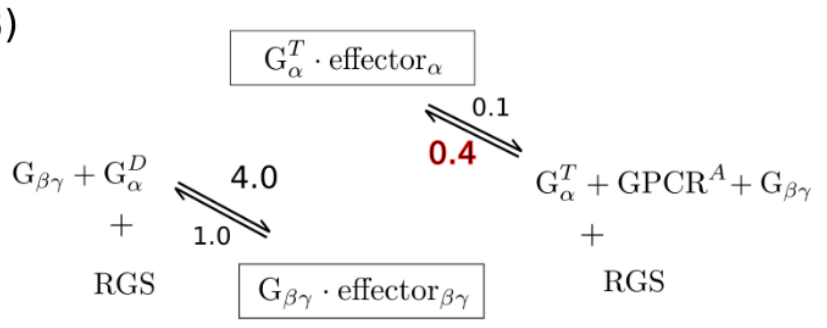

\section{C)}
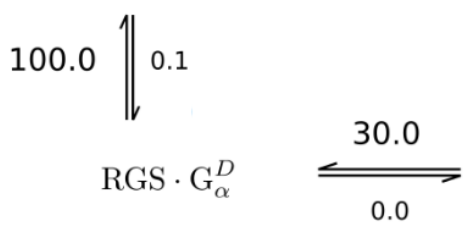

RGS

D)

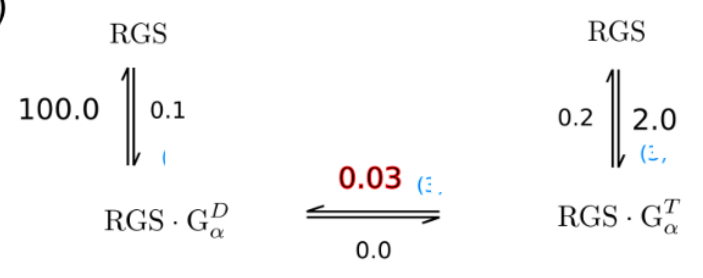

Figure S6. Parameters modified from their wild-type values (Fig. S1) to simulate effect of degraded A) interaction between G $\alpha$ and GPCR, B) G $\alpha$ and effector, C) G $\alpha$ and RGS, and D) catalytic rate for GTP hydrolysis.

To 'abrogate' the interaction, the forward rate was set to 0 .

In each case, the parameter(s) for only one half of the GNAO1 population were changed, to emulate an autosomal dominant scenario.

The rescuing of the signal shape by increasing the level of agonist was simulated by doubling the agonist amount, and, when the rescue seemed to call for reducing the level of agonist, by taking $1 / 10$ of the wild type value. 
Figure S7. Rescuing the signal by increasing the level of agonist. In all cases, main figure shows the wild type (dotted) and mutant signal (full line). Insets: rescuing the signal modified at the interface with GPCR and effector by doubling the amount of agonist. "Abrogated" interaction refers to the forward interaction rate set to 0 . 

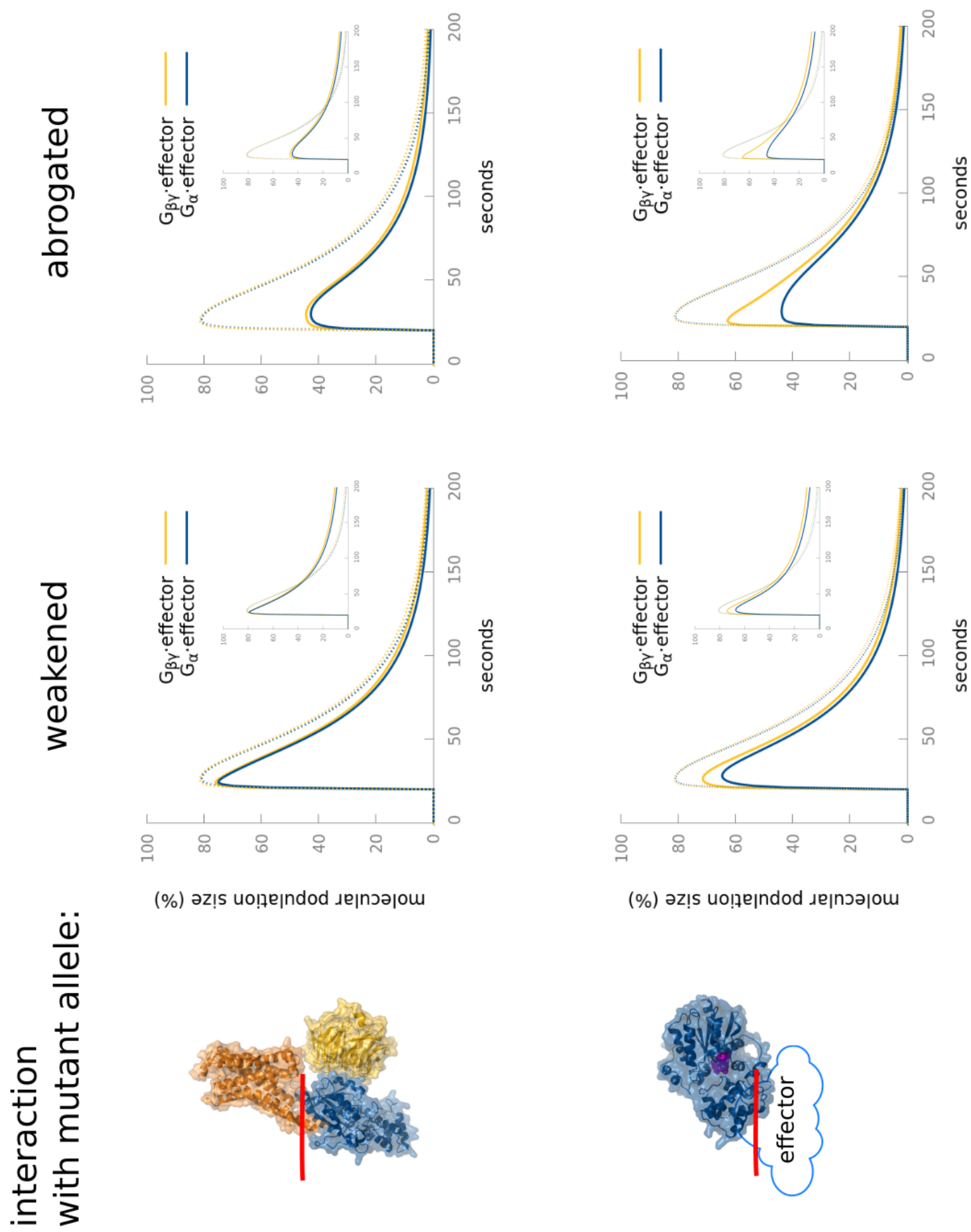

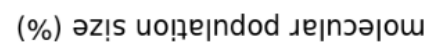

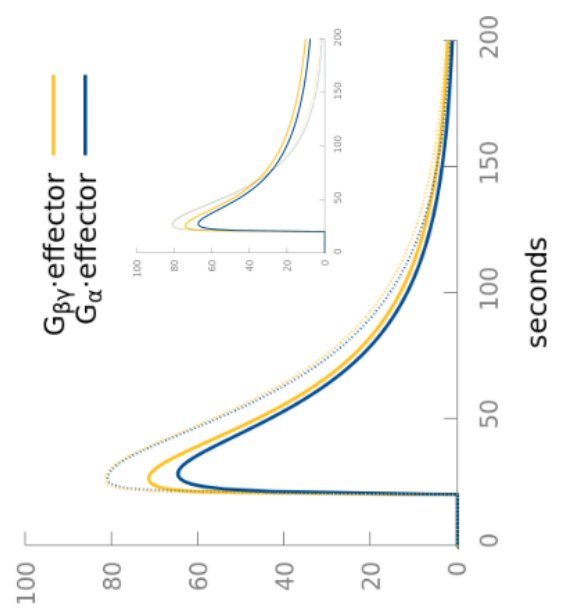

(\%) әz!̣ uo!̣eןndod ıерпәәош

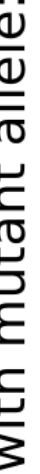
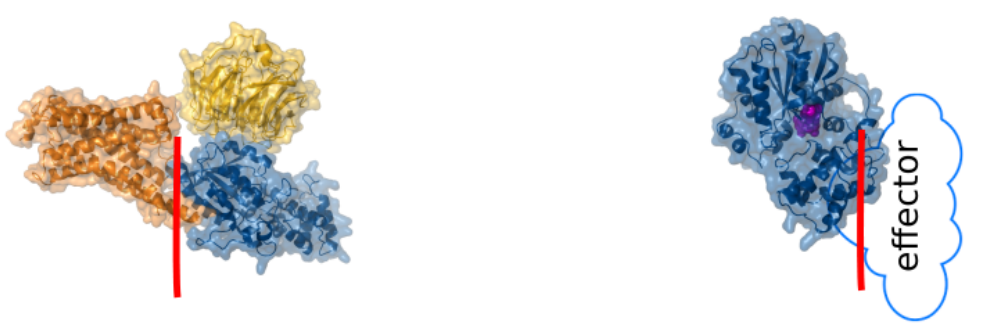

$$
{ }^{\infty} \mathfrak{D} \cdot \text { UDdD }
$$

${ }^{\infty}$ тоұวӘШә $\cdot{ }^{\infty}$ D 
Figure S8. Rescuing the signal by decreasing the level of agonist. A) Modification that lowers the rate of RGS binding to Galpha. B) Modification that lowers the catalysis rate. In all cases, main figure shows the wild type (dotted) and mutant signal (full line). Insets: rescuing the signal modified by mutation in the catalytic pocket or at the interface with RGS, by reducing the amount of agonist to $1 / 10$ th of the original value. 

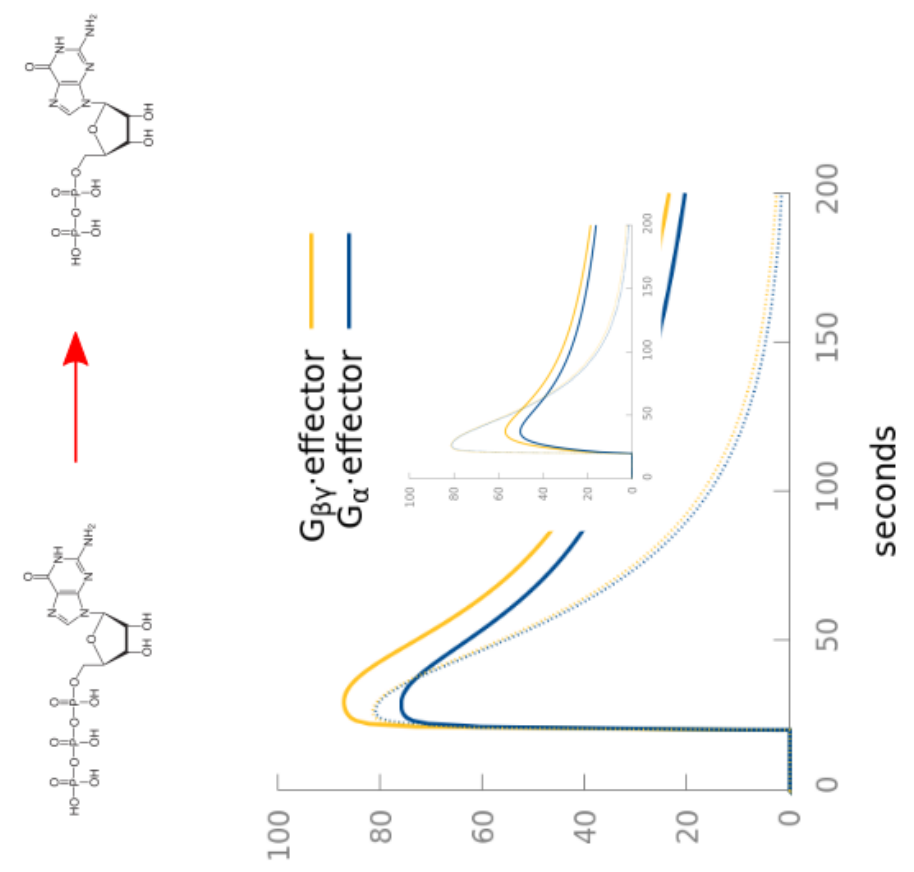

$\widehat{\boldsymbol{m}}$
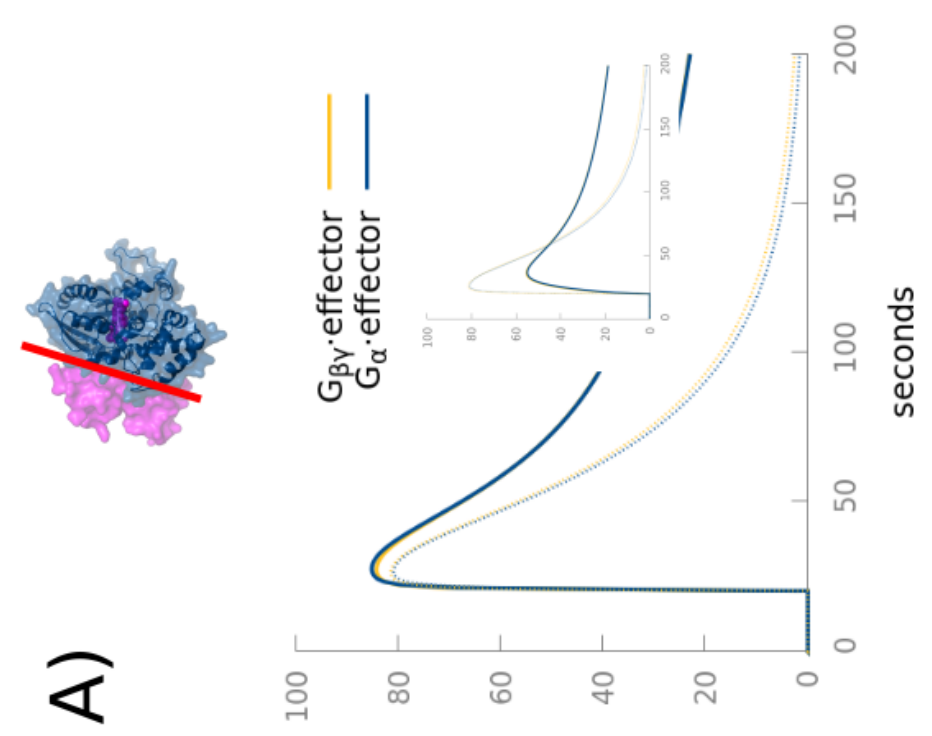

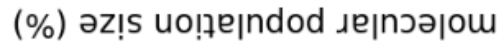




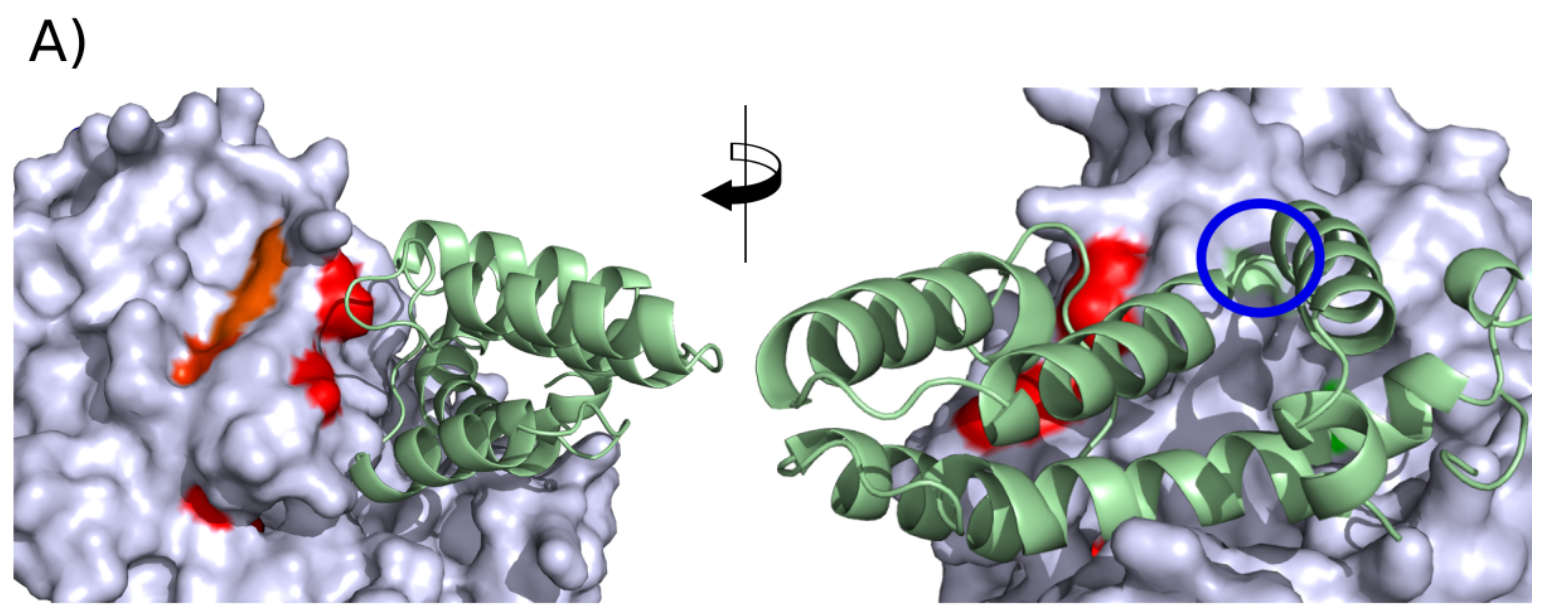

B)

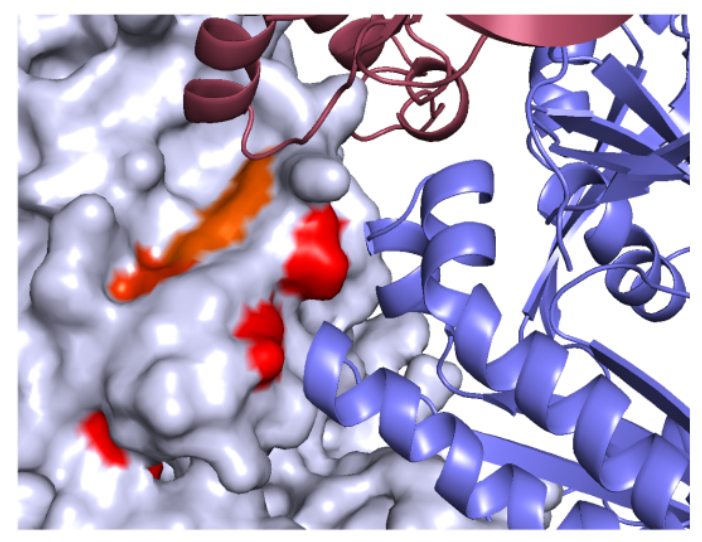

Figure S9. (A) Location of the MD cluster (red, orange) with respect to RGS. Blue circle highlights the position of the known mutation that abolishes the interaction with RGS [10]. Pale green: RGS. (B) Location of the MD cluster with respect to adenylate cyclase (red: crystallographic from [3]; blue: hypothetical, from [5]). 
bioRxiv preprint doi: https://doi.org/10.1101/232058; this version posted December 11,2017 . The copyright holder for this preprint (which was not certified by peer review) is the author/funder. All rights reserved. No reuse allowed without permission.

\section{Forme fruste of GNAO1 phenotype: an example}

(To be included after the Kelly et al.publication appears in the press) 


\section{Variants, phenotypes, and treatments}

\section{Drug dictionary, from Drugbank [11]}

Bethanechol: muscarinic receptor agonist.

Carbidopa: used in parkinson disease to reduce peripheral adverse effects of levodopa. It has no antiparkinson actions by itself.

Clobazam: a benzodiazepine (GABA receptor enhancer) with very long half-life. Increases the duration of time for which the chloride ionopore is open. As a result, hyper polarization and stabilization of the membrane occur as the post-synaptic inhibitory effect of GABA is enhanced.

Clonazepam: a benzodiazepine (GABA receptor enhancer) with long half-life.

Clonidine: stimulates a-adrenergic receptors;

Diazepam: a benzodiazepine (GABA receptor enhancer) with medium-length half-life.

Fentanyl: an opioid analgesic. activity is, most likely, due to its conversion to morphine. Opioids close N-type voltageoperated calcium channels (OP2-receptor agonist) and open calcium-dependent inwardly rectifying potassium channels (OP3 and OP1 receptor agonist). This results in hypopolarization and reduced neuronal excitability.

Lacosamide: A functionalized amino acid. Inhibits sodium channels. Only affects those neurons which are depolarized or active for long periods of time, typical of neurons at the focus of an epileptic seizure, as opposed to other antiepileptic drugs such as carbamazepine or lamotrigine which slow the recovery from inactivation and reduce the ability of neurons to fire action potentials.

Lamotrigine: sodium channel regulation.

Levetiracetam: binds to the synaptic vesicle protein SV2A, inhibiting neurotransmitter release.

Levodopa: precursor of dopamine. It is rapidly taken up by dopaminergic neurons and converted to dopamine.

Midazolam: a benzodiazepine (GABA receptor enhancer) with short half-life.

Oxcarbazepine: sodium channel inhibition.

Phenobarbital: acts as a nonselective central nervous system depressant. It promotes binding to inhibitory gammaaminobutyric acid subtype receptors, and modulates chloride currents through receptor channels. This has the effect of elevating seizure threshold and reducing the spread of seizure activity from a seizure focus.

Pimozide: binds and inhibits the dopamine D2 receptor in the CNS.

Prednisone: a glucocorticoid receptor agonist. The most commonly-prescribed corticosteroid, used to treat allograft rejection, asthma, systemic lupus erythematosus, and many other inflammatory states.

Risperidone: high affinity for 5-hydrotryptamine (5-HT) and dopamine D2 receptors; also binds at alpha(1)-adrenergic receptors. Blockade of dopaminergic D2 receptors in the limbic system alleviates positive symptoms of schizophrenia such as hallucinations, delusions, and erratic behavior and speech. Blockade of serotonergic 5-HT2 receptors in the mesocortical tract, causes an excess of dopamine and an increase in dopamine transmission, resulting in an increase in dopamine transmission and an elimination of core negative symptoms. Dopamine receptors in the nigrostriatal pathway are not affected by risperidone and extrapyramidal effects are avoided.

Tetrabenazine: promotes depletion of monoamine neurotransmitters serotonin, norepinephrine, and dopamine. Tetrabenazine is a reversible human vesicular monoamine transporter type 2 inhibitor

Topiramate: blocks the action potentials elicited repetitively by a sustained depolarization of the neurons in a timedependent manner, suggesting a state-dependent sodium channel blocking action; also augments the activity of the neurotransmitter GABA at some subtypes of the GABAA receptor

Trazodone: inhibits serotonin reuptake pump at the presynaptic neuronal membrane and does not affect the reuptake of norepinephrine or dopamine;

Trihexyphenidyl: muscarinic acetylcholine receptor antagonist with preference for M1. (G $\alpha$ is believed to interact with M2 and M4.) Also thought to enhance D1-mediated and reduce D2-mediated dopamine signaling. Also thought to increase the availability of dopamine, through blocking of dopamine reuptake and storage (12). Note: Most patients with dopa-responsive dystonia also improve with anticholinergic drugs (13).

Valproic acid: The drug's anticonvulsant activity may be related to increased brain concentrations of GABA. May also work by suppressing repetitive neuronal firing through inhibition of voltage-sensitive sodium channels.

Zonisamide: believed that the drug blocks sodium and calcium channels, which leads to the suppression of neuronal hypersynchronization (i.e. convulsions). 
Table S2. Variants, phenotypes and treatments reported in the literature. The reference numbers refer to references in this document, rather than in the main text. Shorthands:

E: epilepsy-related symptoms. MD: movement disorder-related symptoms

IF: interface. NTR: nucleotide release. KD: ketogenic diet. NE: neuronal excitability. GTCs: generalized tonic-clonic seizures.

"GABA $\uparrow "$ may stand for any type of enhancement of gamma-aminobutyric acid (GABA) effects, either though the enhanced quantity of GABA itself, stimulation of GABA receptors or extended opening of chloride ionopores. M1-5: muscarinic acetylcholine receptors M1 through M5.

For the medication discussion and full list of ineffective medication see the original reference (where applicable). 


\begin{tabular}{|c|c|c|c|c|}
\hline 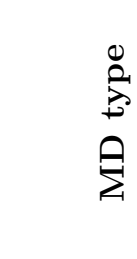 & 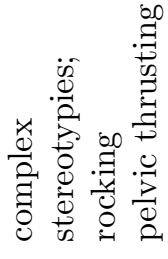 & 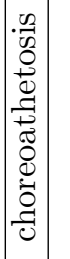 & 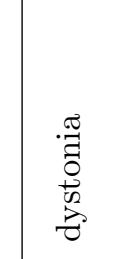 & 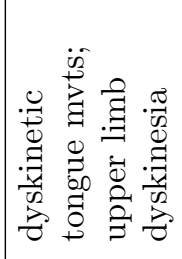 \\
\hline 苞 & $\begin{array}{l}\text { 兵 } \\
\text { О } \\
\text { 兵 }\end{array}$ & 侄 & 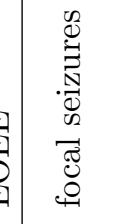 & 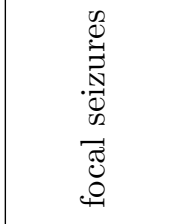 \\
\hline 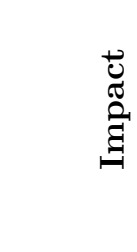 & 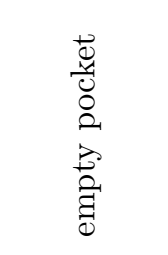 & 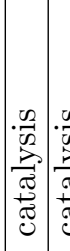 & 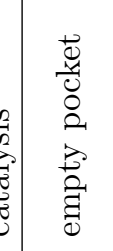 & 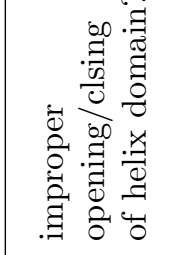 \\
\hline 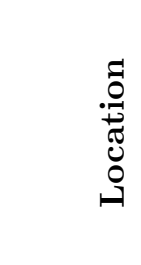 & 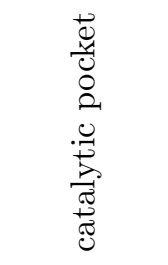 & 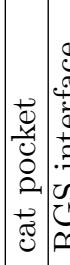 & 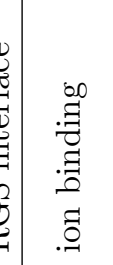 & 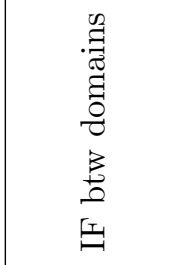 \\
\hline 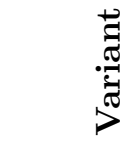 & 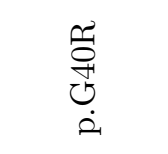 & 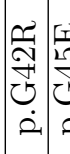 & 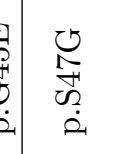 & 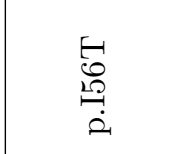 \\
\hline 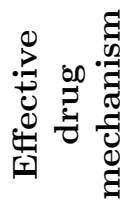 & $\frac{\infty}{a}$ & $\stackrel{\pi}{\Rightarrow}$ & 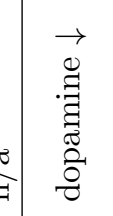 & $\frac{\pi}{\nexists}$ \\
\hline 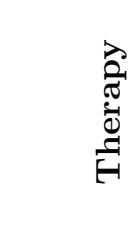 & 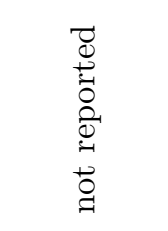 & 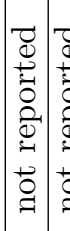 & 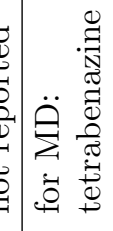 & 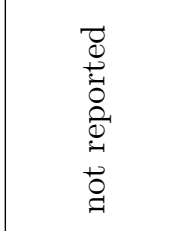 \\
\hline$\frac{\stackrel{g}{d}}{\stackrel{d}{\alpha}}$ & $\begin{array}{l}\text { 至 } \\
\text { 去 } \\
\text { 空 }\end{array}$ & $\left|\begin{array}{c}x \\
\pm \\
\theta \\
\vdots\end{array}\right|$ & $\begin{array}{l}\text { 至 } \\
\text { 去 } \\
\text { 空 }\end{array}$ & 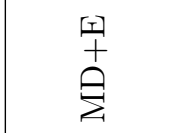 \\
\hline $\begin{array}{l}x \\
\text { D. } \\
\text { Wh }\end{array}$ & II & $\Sigma$ & $\Sigma$ & I \\
\hline \multirow[t]{2}{*}{ 崩 } & $\underset{二}{ت}$ & $\stackrel{12}{-1}$ & $\stackrel{\simeq}{二}$ & $\stackrel{\bumpeq}{\neg}$ \\
\hline & - & $\sim \curvearrowright$ & $\vec{r}$ & 10 \\
\hline
\end{tabular}




\begin{tabular}{|c|c|c|c|c|c|c|c|}
\hline 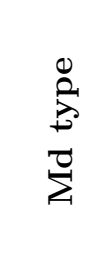 & & 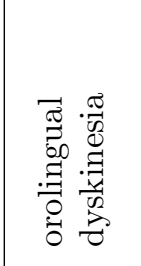 & 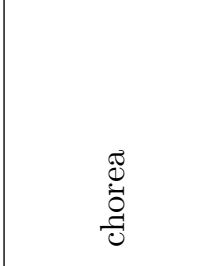 & 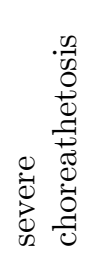 & 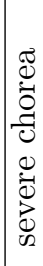 & 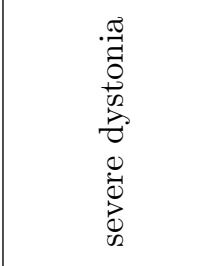 & 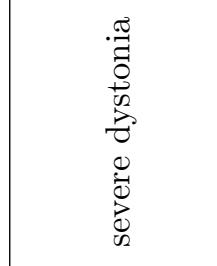 \\
\hline $\begin{array}{l}0 \\
\substack{0 \\
0 \\
01} \\
\text { al }\end{array}$ & 空 & 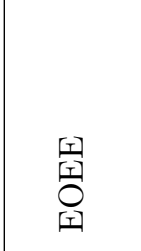 & 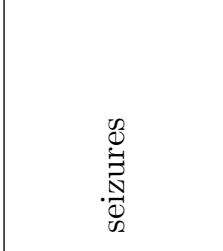 & 兵 & 侄 & 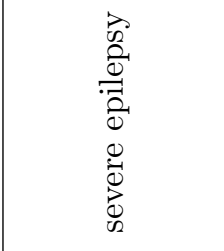 & 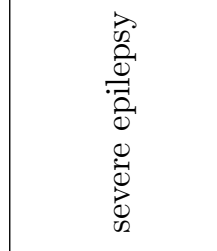 \\
\hline 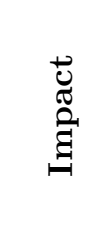 & $\frac{\frac{n}{0}}{\frac{1}{\pi}}$ & $\begin{array}{l}\frac{\pi}{\sigma} \\
\frac{\pi}{7} \\
\frac{\pi}{\pi} \\
\frac{\pi}{0}\end{array}$ & 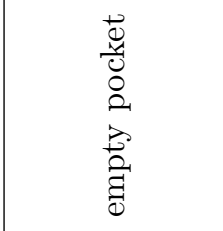 & 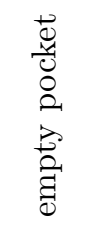 & 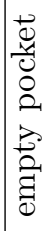 & 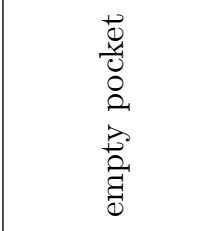 & 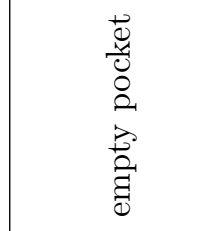 \\
\hline 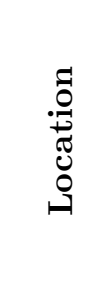 & 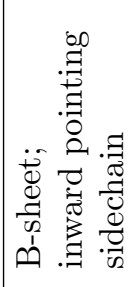 & & 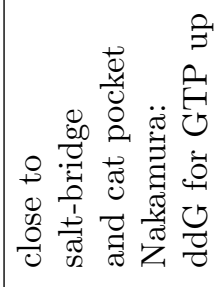 & & & & \\
\hline 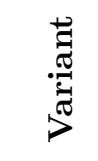 & & 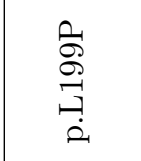 & 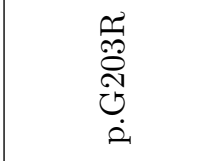 & 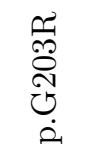 & 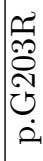 & 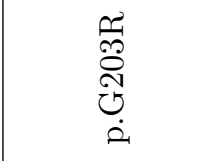 & 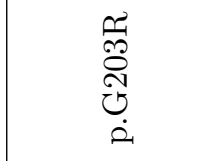 \\
\hline 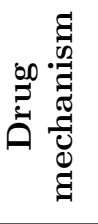 & 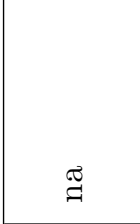 & $\overrightarrow{\text { 至 }}$ & 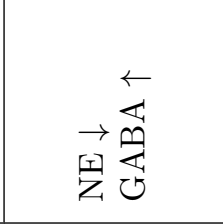 & 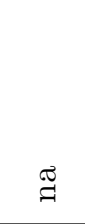 & $\underset{\exists}{\approx}$ & 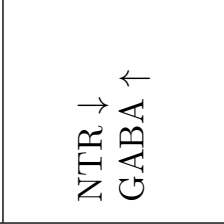 & 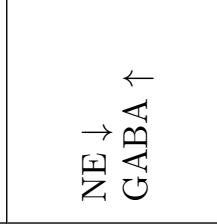 \\
\hline 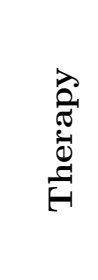 & 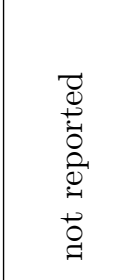 & 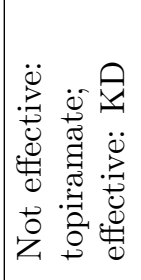 & 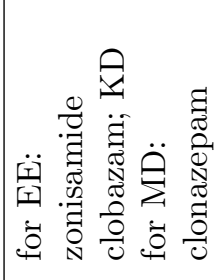 & $\begin{array}{l}\overrightarrow{0} \\
\mathbb{0} \\
00 \\
000 \\
0 \\
0 \\
0 \\
0\end{array}$ & 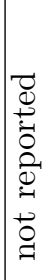 & 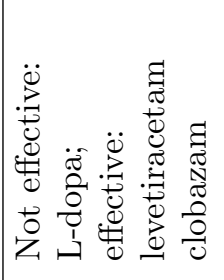 & 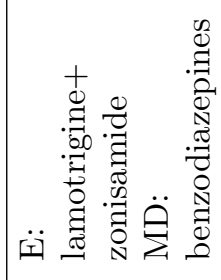 \\
\hline$\frac{0}{d}$ & 또 & $\begin{array}{l}\text { 되 } \\
\stackrel{+}{\ominus} \\
\text { 究 }\end{array}$ & $\begin{array}{l}\stackrel{1}{+} \\
\stackrel{+}{\mid}\end{array}$ & $\begin{array}{l}\text { II } \\
\stackrel{+}{\ominus} \\
\text { 至 }\end{array}$ & 空 & $\begin{array}{l}\text { 되 } \\
\text { 圭 } \\
\text { 空 }\end{array}$ & 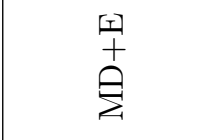 \\
\hline 孞 & II & II & $\Sigma$ & II & I & 工 & I \\
\hline 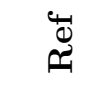 & $\stackrel{\infty}{-1}$ & $\stackrel{\leftrightarrow}{\longrightarrow}$ & 尺ి & $\overrightarrow{\mathrm{N}}$ & নิ & $\ddot{\sim}$ & $\approx \mathfrak{N}$ \\
\hline & 0 & $\wedge$ & $\infty$ & $\sigma$ & $\stackrel{ }{-1}$ & $\exists$ & $\stackrel{\sim}{-}$ \\
\hline
\end{tabular}




\begin{tabular}{|c|c|c|c|c|}
\hline 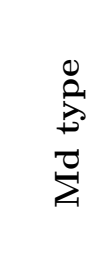 & 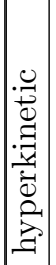 & 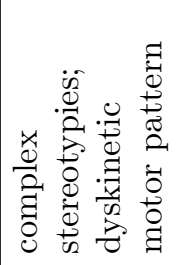 & 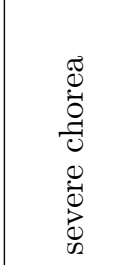 & 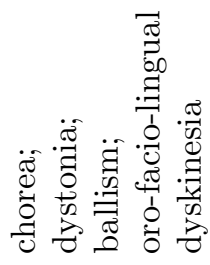 \\
\hline 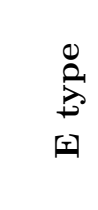 & $\mid \begin{array}{c}n \\
0 \\
-1 \\
0\end{array}$ & 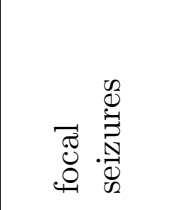 & 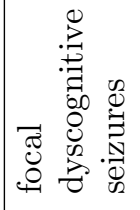 & $\overbrace{0}^{\infty}$ \\
\hline 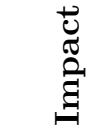 & 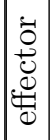 & $\begin{array}{l}\stackrel{0}{0} \\
\text { 苞 } \\
\text { 虫 }\end{array}$ & 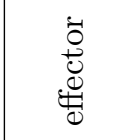 & 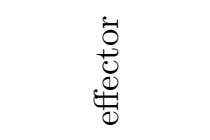 \\
\hline 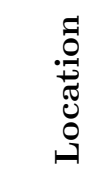 & 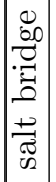 & 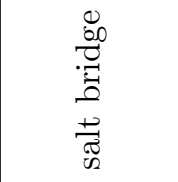 & 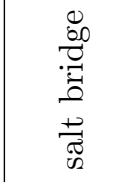 & 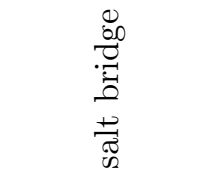 \\
\hline 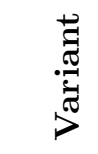 & 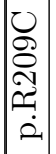 & 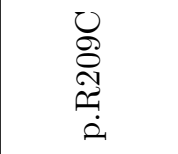 & $\begin{array}{l}0 \\
\stackrel{0}{0} \\
\stackrel{\tilde{N}}{2} \\
\dot{2}\end{array}$ & $\begin{array}{l}\circlearrowright \\
\mathscr{\partial} \\
\stackrel{\tilde{N}}{2} \\
\dot{2}\end{array}$ \\
\hline 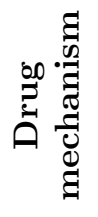 & $\underset{\Xi}{\exists}$ & $\underset{\exists}{\overparen{E}}$ & $\underset{\widetilde{J}}{\widetilde{J}}$ & 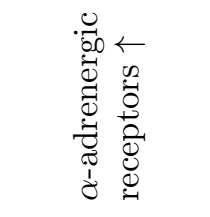 \\
\hline 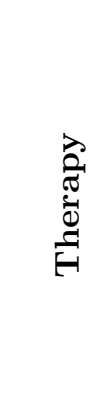 & 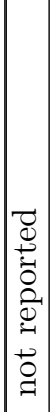 & 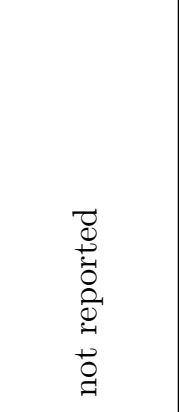 & 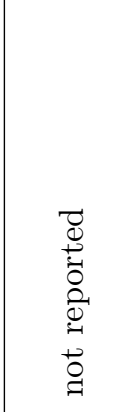 & 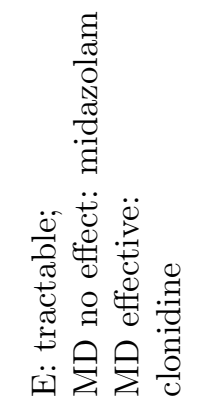 \\
\hline$\frac{\stackrel{g}{d}}{\stackrel{d}{a}}$ & 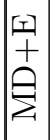 & $\begin{array}{l}\text { 㛙 } \\
\stackrel{+}{\ominus}\end{array}$ & $\begin{array}{l}\text { 㛙 } \\
\stackrel{+}{\ominus}\end{array}$ & $\begin{array}{l}\text { 되 } \\
\stackrel{+}{\ominus} \\
\stackrel{\text { 足 }}{2}\end{array}$ \\
\hline$\stackrel{x}{\infty}$ & $\Sigma$ & $\Sigma$ & [工 & 工工 \\
\hline 崩 & $\bumpeq$ & $\bumpeq$ & సิ & $\stackrel{\sim}{\sim}$ \\
\hline & 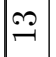 & $\underset{二}{ت}$ & $\stackrel{102}{\rightarrow}$ & $\stackrel{\bullet}{\bullet}$ \\
\hline
\end{tabular}




\begin{tabular}{|c|c|c|c|c|c|c|c|}
\hline $\begin{array}{l}0 \\
\substack{0 \\
D} \\
\sum_{i}^{0}\end{array}$ & 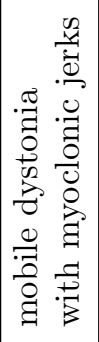 & 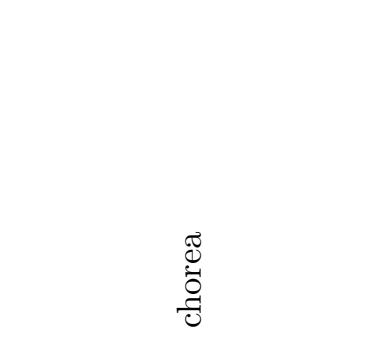 & 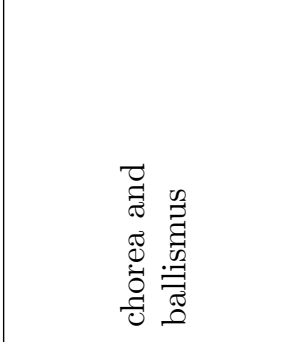 & 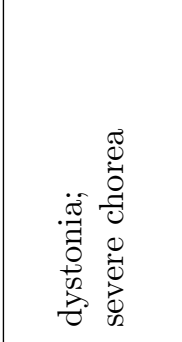 & 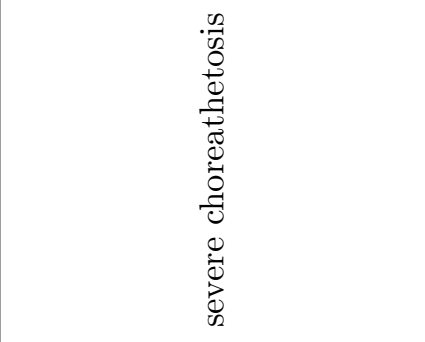 & 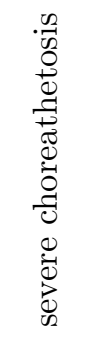 & 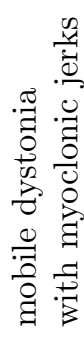 \\
\hline 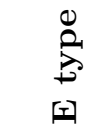 & & & & & & & \\
\hline 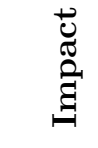 & 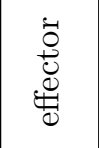 & 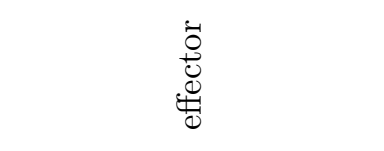 & 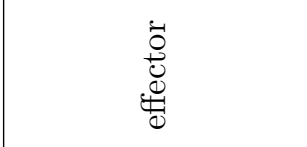 & 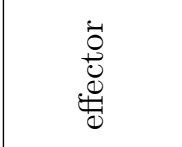 & 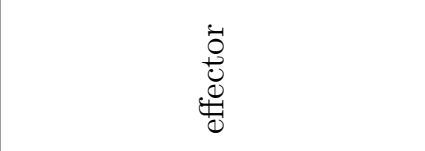 & 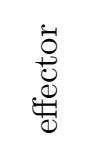 & 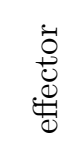 \\
\hline 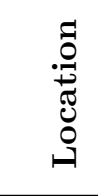 & 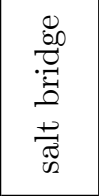 & 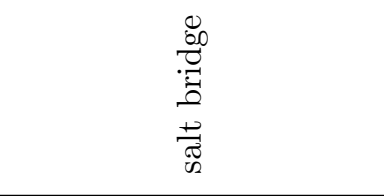 & 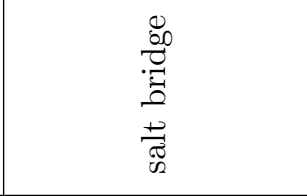 & 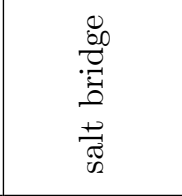 & 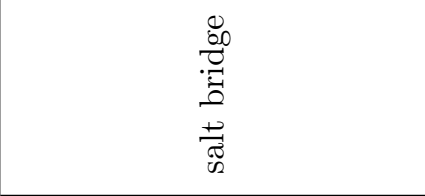 & 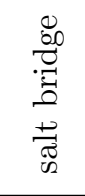 & 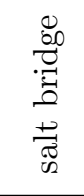 \\
\hline 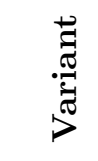 & $\begin{array}{l}\vec{\partial} \\
\stackrel{2}{0} \\
\stackrel{1}{1} \\
\dot{2}\end{array}$ & 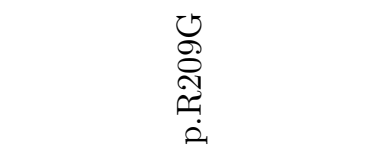 & 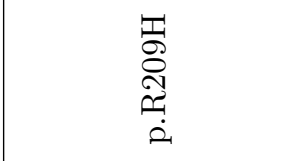 & 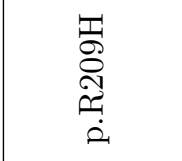 & 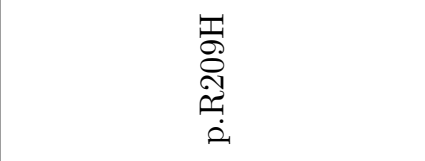 & 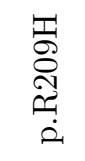 & 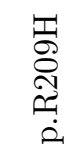 \\
\hline 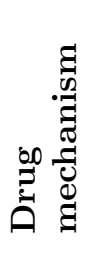 & 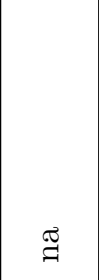 & 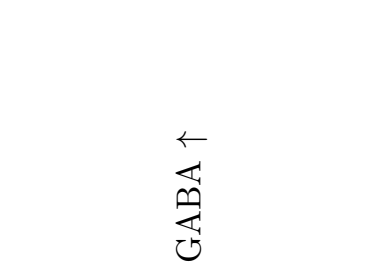 & 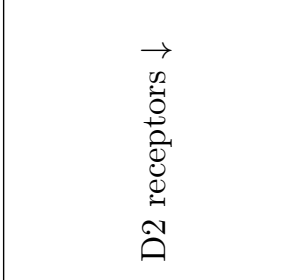 & 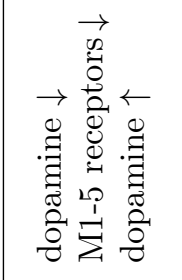 & 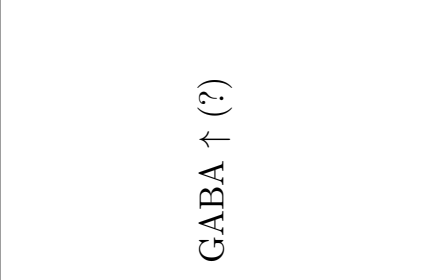 & 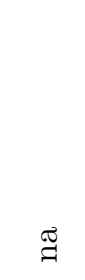 & $\dddot{\Xi}$ \\
\hline 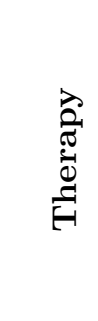 & 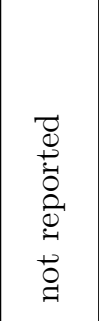 & 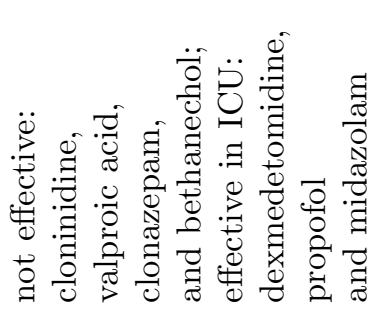 & 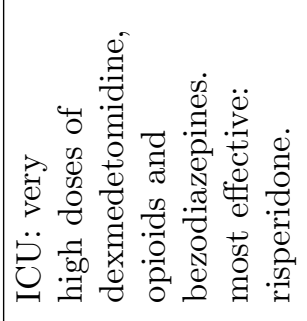 & 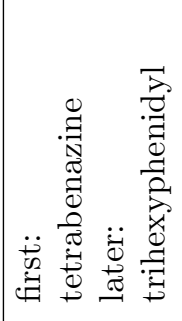 & 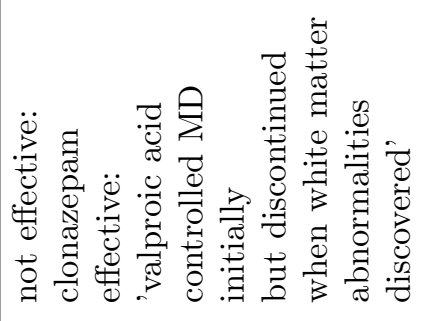 & 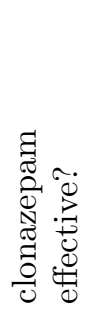 & 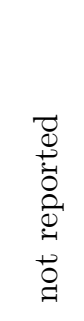 \\
\hline$\frac{d}{d}$ & $\stackrel{\ominus}{\mathrm{z}}$ & $\stackrel{\ominus}{\mathrm{z}}$ & $\stackrel{\ominus}{\Sigma}$ & $\stackrel{\ominus}{\mathrm{Z}}$ & $\stackrel{\ominus}{\Sigma}$ & $\stackrel{\ominus}{\mathrm{i}}$ & $\stackrel{\ominus}{\Sigma}$ \\
\hline ڤึ & $\Sigma$ & 厌 & $\Sigma$ & $\Sigma$ & $\Sigma$ & $\Sigma$ & $\Sigma$ \\
\hline \multirow[t]{2}{*}{ 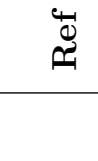 } & $\stackrel{2}{\mathrm{~N}}$ & $\stackrel{\sim}{\sim}$ & $\stackrel{\sim}{\sim}$ & $\stackrel{\sim}{\sim}$ & $\stackrel{\infty}{\sim}$ & $\stackrel{\infty}{\sim}$ & $\stackrel{2}{\mathrm{~N}}$ \\
\hline & $\bumpeq$ & $\stackrel{\infty}{\sim}$ & $\stackrel{\leftrightarrow}{\sim}$ & $\stackrel{\curvearrowright}{\curvearrowright}$ & $\vec{\sim}$ & $\approx$ & $\stackrel{2}{\sim}$ \\
\hline
\end{tabular}




\begin{tabular}{|c|c|c|c|c|}
\hline 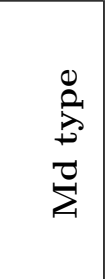 & चี & 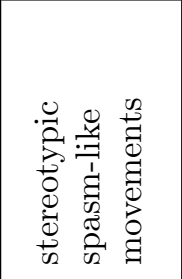 & 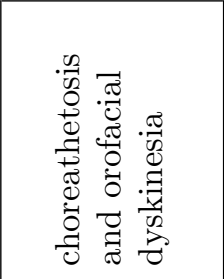 & 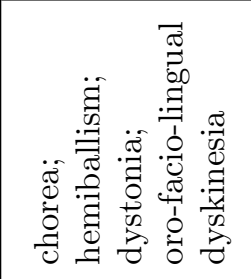 \\
\hline 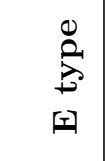 & 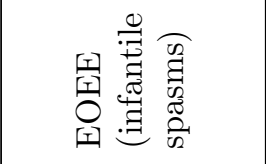 & \begin{tabular}{l}
\multicolumn{1}{|r|}{} \\
空 \\
厌
\end{tabular} & & \\
\hline $\begin{array}{l}\stackrel{u}{0} \\
\tilde{\sigma} \\
\stackrel{\Xi}{\Xi}\end{array}$ & 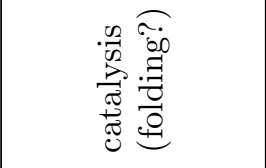 & & & $\begin{array}{l}\ddot{0} \\
\stackrel{0}{0} \\
\stackrel{0}{0}\end{array}$ \\
\hline 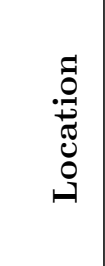 & 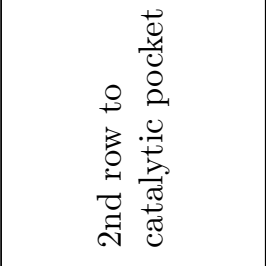 & 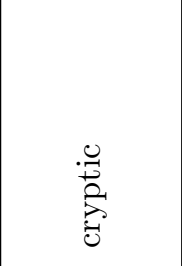 & 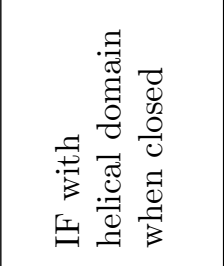 & 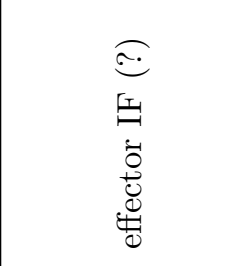 \\
\hline 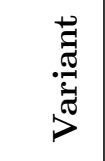 & 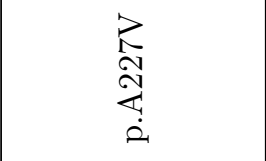 & 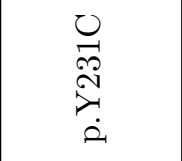 & 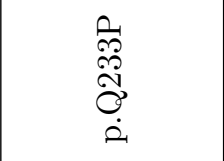 & 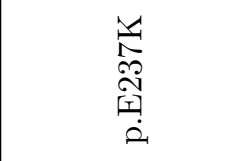 \\
\hline 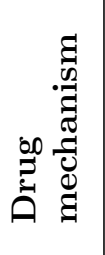 & 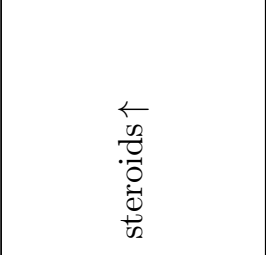 & & 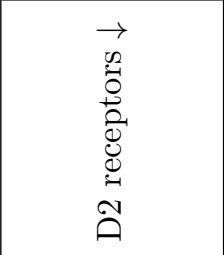 & 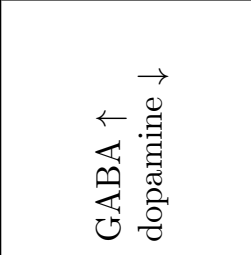 \\
\hline 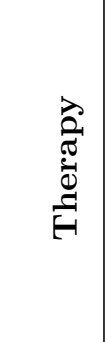 & 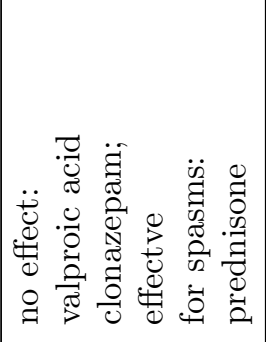 & 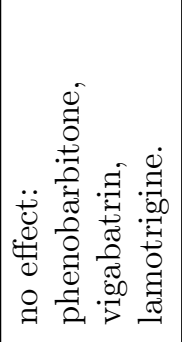 & 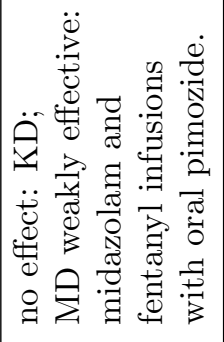 & 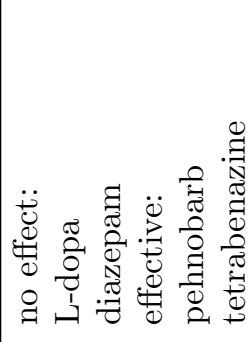 \\
\hline$\frac{\stackrel{d}{d}}{\stackrel{d}{Q}}$ & $\begin{array}{l}\text { 玟 } \\
\stackrel{+}{\ominus} \\
\stackrel{2}{\Sigma}\end{array}$ & $\begin{array}{l}\text { 垶 } \\
\text { 妾 }\end{array}$ & $\stackrel{\ominus}{\Sigma}$ & $\stackrel{\ominus}{\mathrm{z}}$ \\
\hline 希 & 厌 & 工 & 工 & $\Sigma$ \\
\hline \multirow[t]{2}{*}{ 式 } & ন & $\stackrel{\infty}{-}$ & $\stackrel{\text { ন }}{ }$ & $\stackrel{\sim}{N}$ \\
\hline & $\overleftrightarrow{N}$ & $\stackrel{2}{N}$ & $\stackrel{\sim}{\sim}$ & ล \\
\hline
\end{tabular}




\begin{tabular}{|c|c|c|c|c|c|c|c|c|c|}
\hline 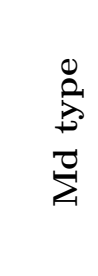 & 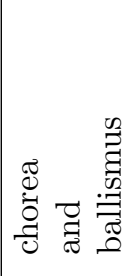 & 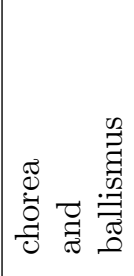 & 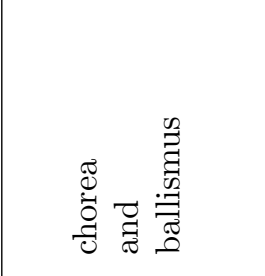 & 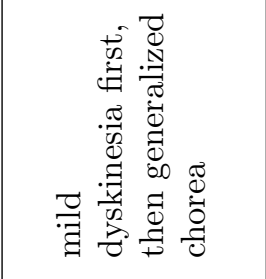 & 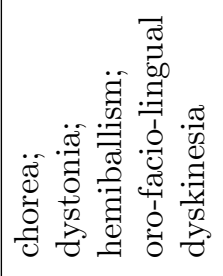 & 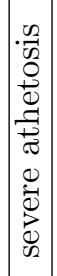 & 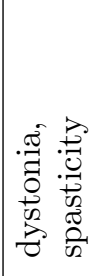 & 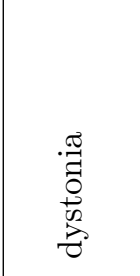 & \\
\hline$\underset{\text { 总 }}{\stackrel{0}{0}}$ & & & & & & & 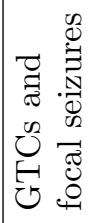 & & 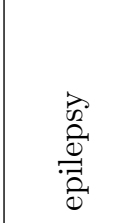 \\
\hline $\begin{array}{l}\ddot{U} \\
\tilde{\Xi} \\
\stackrel{\Xi}{\Xi}\end{array}$ & 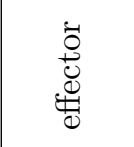 & 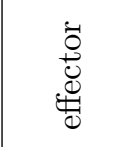 & 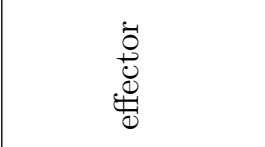 & 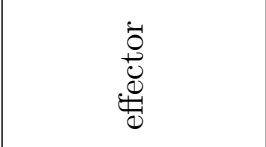 & $\begin{array}{l}\tilde{0} \\
\stackrel{d}{0} \\
\stackrel{\mathscr{C}}{0}\end{array}$ & 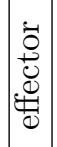 & 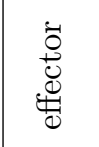 & 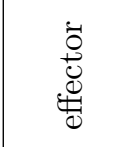 & 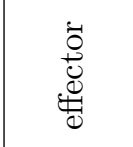 \\
\hline 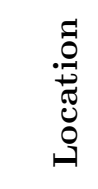 & 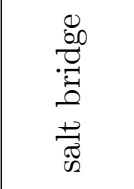 & 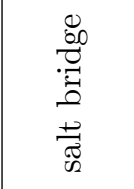 & 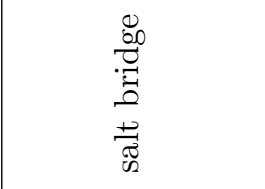 & 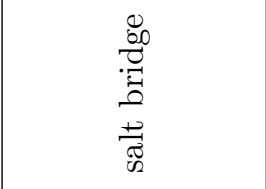 & 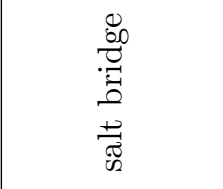 & 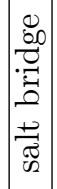 & 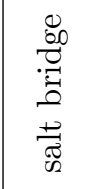 & 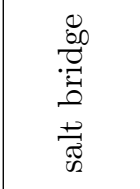 & 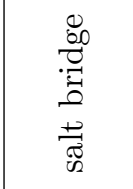 \\
\hline 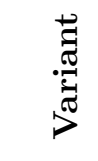 & 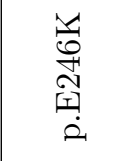 & 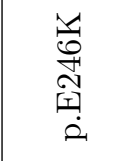 & 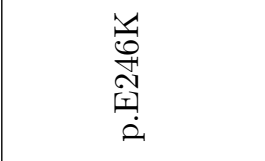 & 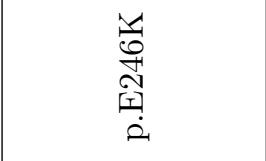 & 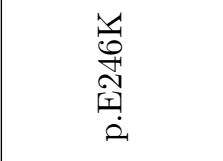 & 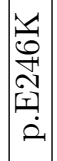 & $\begin{array}{l}\text { Uु } \\
\stackrel{0}{1} \\
\text { II } \\
\text { İ } \\
\text { ¿ }\end{array}$ & 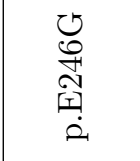 & 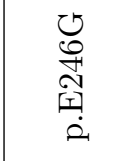 \\
\hline 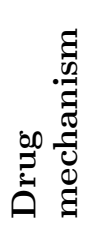 & & 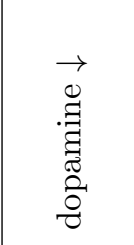 & 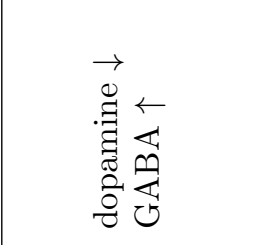 & 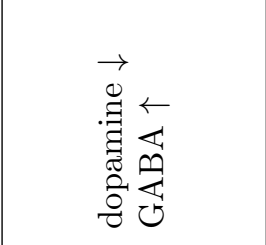 & 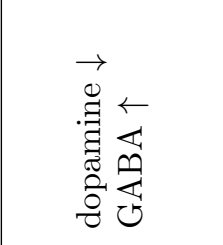 & 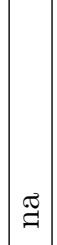 & 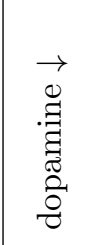 & & 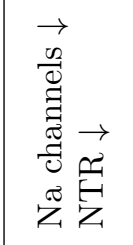 \\
\hline 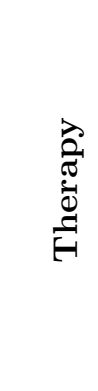 & 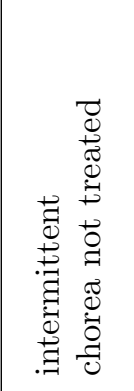 & 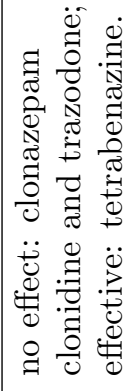 & 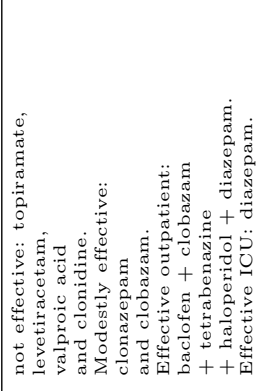 & 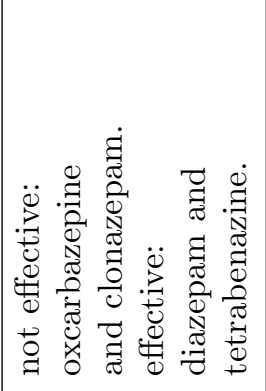 & 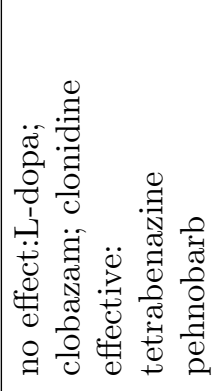 & $\mid \begin{array}{l}0 \\
0 \\
0 \\
0 \\
0 \\
0 \\
00 \\
0 \\
0 \\
0 \\
0 \\
0\end{array}$ & 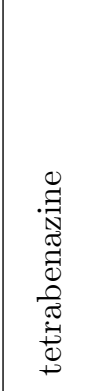 & 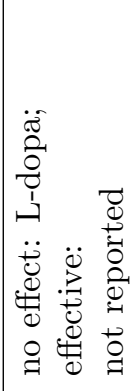 & 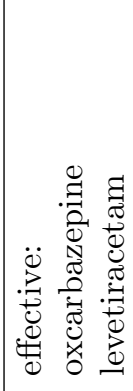 \\
\hline$\frac{\stackrel{g}{d}}{\stackrel{d}{Q}}$ & $\stackrel{\ominus}{i}$ & $\stackrel{\ominus}{\mathrm{i}}$ & $\stackrel{\ominus}{\mathrm{z}}$ & $\stackrel{\ominus}{\mathrm{z}}$ & $\stackrel{\ominus}{\mathrm{z}}$ & 空 & 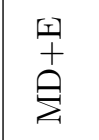 & $\stackrel{\ominus}{\mathrm{z}}$ & 되 \\
\hline$\stackrel{x}{\omega}^{x}$ & $\Sigma$ & I & II & $\Sigma$ & II & II & $\Sigma$ & $\Sigma$ & II \\
\hline 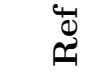 & $\stackrel{\sim}{\sim}$ & $\stackrel{\sim}{*}$ & $\stackrel{\sim}{\sim}$ & $\stackrel{\sim}{\sim}$ & $\stackrel{H}{N}$ & নิ & $\stackrel{ }{\simeq}$ & $\stackrel{9}{\sim}$ & $\stackrel{\leftrightarrow}{*}$ \\
\hline & $\stackrel{\infty}{\sim}$ & $\stackrel{\sim}{2}$ & คి & $\vec{\sigma}$ & ஸे & $\approx$ & ले & $\stackrel{100}{\circ}$ & $\stackrel{\leftrightarrow}{\circ}$ \\
\hline
\end{tabular}



not certified by peer review) is the author/funder. All rights reserved. No reuse allowed without permission.

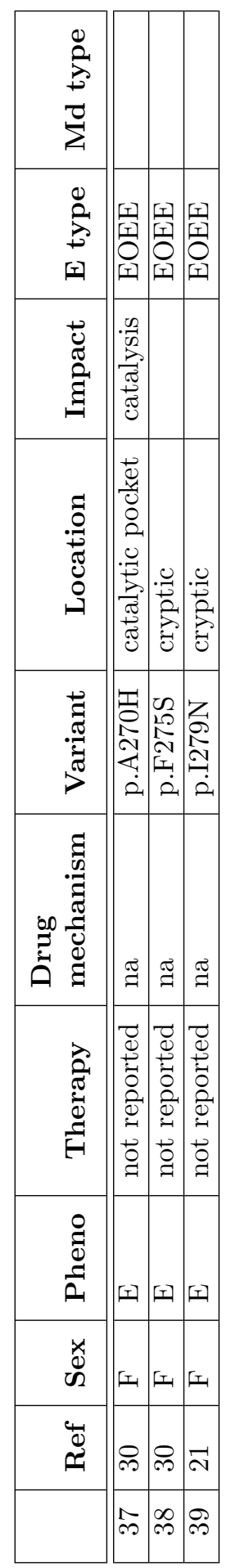




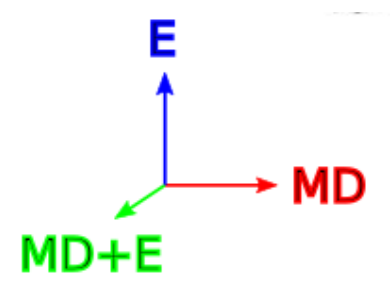

Figure S11. RGB coloring scheme. The RGB coloring scheme in the main text, Fig. 3, was used to indicate that for some positions different phenotypes have been reported in literature. For each position three values were calculated: $M D=$ number of patients with MD-only phenotype, $E=$ number of patients with E-only phenotype, and $C=$ number of patients with combined phenotype. With $N=\sqrt{M D^{2}+E^{2}+C^{2}}$, the color was assigned according to RGB coloring scheme with RGB vector evaluated as $(M D / N, C / N, E / N)$, thus making pure MD completely red, pure E completely blue, and pure $\mathrm{MD}+\mathrm{E}$ completely green, with all cases of mixed reports having color somewhere in between. For example, the position for which one patient was reported as E, and one as E+MD would be colored cyan (blue + green). 


\section{References}

[1] Jiang M, Bajpayee NS (2009) Molecular mechanisms of go signaling. Neurosignals 17: $23-41$.

[2] Slep KC, Kercher MA, Wieland T, Chen CK, Simon MI, et al. (2008) Molecular architecture of g $\alpha \mathrm{o}$ and the structural basis for rgs16-mediated deactivation. Proceedings of the National Academy of Sciences 105: 6243-6248.

[3] Tesmer JJ, Sunahara RK, Gilman AG, Sprang SR (1997) Crystal structure of the catalytic domains of adenylyl cyclase in a complex with gs $\alpha \cdot \operatorname{gtp} \gamma$ s. Science 278: 1907-1916.

[4] Van Keulen SC, Rothlisberger U (2016) Effect of n-terminal myristoylation on the active conformation of g $\alpha$ i 1-gtp. Biochemistry 56: 271-280.

[5] Van Keulen SC, Rothlisberger U (2017) Exploring the inhibition mechanism of adenylyl cyclase type 5 by n-terminal myristoylated gai1. PLoS computational biology 13: e1005673.

[6] Calebiro D, Nikolaev VO, Gagliani MC, de Filippis T, Dees C, et al. (2009) Persistent cAMPsignals triggered by internalized G-protein-coupled receptors. PLoS biology 7: e1000172.

[7] Zhong H, Wade SM, Woolf PJ, Linderman JJ, Traynor JR, et al. (2003) A spatial focusing model for g protein signals. Journal of Biological Chemistry 278: 7278-7284.

[8] Yu B, Simon MI (1998) Interaction of the xanthine nucleotide binding goo mutant with g proteincoupled receptors. Journal of Biological Chemistry 273: 30183-30188.

[9] Yu B, Slepak VZ, Simon MI (1997) Characterization of a go $\alpha$ mutant that binds xanthine nucleotides. Journal of Biological Chemistry 272: 18015-18019.

[10] Feng H, Sjögren B, Karaj B, Shaw V, Gezer A, et al. (2017) Movement disorder in gnao1 encephalopathy associated with gain-of-function mutations. Neurology 89: 762-770.

[11] Law V, Knox C, Djoumbou Y, Jewison T, Guo AC, et al. (2013) Drugbank 4.0: shedding new light on drug metabolism. Nucleic acids research 42: D1091-D1097.

[12] Shimosato K, Nagao N, Watanabe S, Kitayama S (2003) Suppressive effects of trihexyphenidyl on methamphetamine-induced dopamine release as measured by in vivo microdialysis. Synapse 49: $47-54$.

[13] Jankovic J (2013) Medical treatment of dystonia. Movement Disorders 28: 1001-1012.

[14] Law CY, Chang STL, Cho SY, Yau EKC, Ng GSF, et al. (2015) Clinical whole-exome sequencing reveals a novel missense pathogenic variant of gnao1 in a patient with infantile-onset epilepsy. Clinica Chimica Acta 451: 292-296.

[15] Zhu X, Petrovski S, Xie P, Ruzzo EK, Lu YF, et al. (2015) Whole-exome sequencing in undiagnosed genetic diseases: interpreting 119 trios. Genetics in Medicine 17: 774-781.

[16] Gawlinski P, Posmyk R, Gambin T, Sielicka D, Chorazy M, et al. (2016) Peho syndrome may represent phenotypic expansion at the severe end of the early-onset encephalopathies. Pediatric neurology 60: 83-87.

[17] Danti FR, Galosi S, Romani M, Montomoli M, Carss KJ, et al. (2017) Gnao1 encephalopathy broadening the phenotype and evaluating treatment and outcome. Neurology Genetics 3: e143.

[18] Talvik I, Møller RS, Vaher M, Vaher U, Larsen LH, et al. (2015) Clinical phenotype of de novo gnao1 mutation: case report and review of literature. Child Neurology Open 2. 
[19] Marcé-Grau A, Dalton J, López-Pisón J, García-Jiménez MC, Monge-Galindo L, et al. (2016) Gnao1 encephalopathy: further delineation of a severe neurodevelopmental syndrome affecting females. Orphanet journal of rare diseases 11: 38.

[20] Arya R, Spaeth C, Gilbert DL, Leach JL, Holland KD (2017) Gnao1-associated epileptic encephalopathy and movement disorders: c. $607 \mathrm{~g}$ i a variant represents a probable mutation hotspot with a distinct phenotype. Epileptic Disorders 19: 67-75.

[21] Nakamura K, Kodera H, Akita T, Shiina M, Kato M, et al. (2013) De novo mutations in gnao1, encoding a g $\alpha$ o subunit of heterotrimeric g proteins, cause epileptic encephalopathy. The American Journal of Human Genetics 93: 496-505.

[22] Saitsu H, Fukai R, Ben-Zeev B, Sakai Y, Mimaki M, et al. (2016) Phenotypic spectrum of gnao1 variants: epileptic encephalopathy to involuntary movements with severe developmental delay. European Journal of Human Genetics 24: 129-134.

[23] Schorling DC, Dietel T, Evers C, Hinderhofer K, Korinthenberg R, et al. (2017) Expanding phenotype of de novo mutations in gnao1: four new cases and review of literature. Neuropediatrics 48: $371-377$.

[24] Waak M, Mohammad SS, Coman D, Sinclair K, Copeland L, et al. (2017) Gnao1-related movement disorder with life-threatening exacerbations: movement phenomenology and response to dbs. J Neurol Neurosurg Psychiatry : jnnp-2017.

[25] Menke LA, Engelen M, Alders M, Odekerken VJ, Baas F, et al. (2016) Recurrent gnao1 mutations associated with developmental delay and a movement disorder. Journal of child neurology 31: $1598-1601$.

[26] Ananth AL, Robichaux-Viehoever A, Kim YM, Hanson-Kahn A, Cox R, et al. (2016) Clinical course of six children with gnao1 mutations causing a severe and distinctive movement disorder. Pediatric neurology 59: 81-84.

[27] Dhamija R, Mink JW, Shah BB, Goodkin HP (2016) Gnao1-associated movement disorder. Movement Disorders Clinical Practice 3: 615-617.

[28] Kulkarni N, Tang S, Bhardwaj R, Bernes S, Grebe TA (2016) Progressive movement disorder in brothers carrying a gnao1 mutation responsive to deep brain stimulation. Journal of child neurology 31: 211-214.

[29] Yilmaz S, Turhan T, Ceylaner S, Gökben S, Tekgul H, et al. (2016) Excellent response to deep brain stimulation in a young girl with gnao1-related progressive choreoathetosis. Child's Nervous System 32: 1567-1568.

[30] Phenome E, Consortium ER, Consortium E, et al. (2014) De novo mutations in synaptic transmission genes including dnm1 cause epileptic encephalopathies. The American Journal of Human Genetics 95: 360-370. 